Portland State University

PDXScholar

1987

\title{
An Analysis of a Washington State Policy on the Appraisal of School Administrators by Certificated Subordinates
}

Curtis Alan Miller

Portland State University

Follow this and additional works at: https://pdxscholar.library.pdx.edu/open_access_etds Let us know how access to this document benefits you.

\section{Recommended Citation}

Miller, Curtis Alan, "An Analysis of a Washington State Policy on the Appraisal of School Administrators by Certificated Subordinates" (1987). Dissertations and Theses. Paper 1351.

https://doi.org/10.15760/etd.1350

This Dissertation is brought to you for free and open access. It has been accepted for inclusion in Dissertations and Theses by an authorized administrator of PDXScholar. Please contact us if we can make this document more accessible: pdxscholar@pdx.edu. 
AN ANALYSIS OF A WASHINGTON STATE POLICY ON THE APPRAISAL

OF SCHOOL ADMINISTRATORS BY CERTIFICATED SUBORDINATES

by

CURTIS ALAN MILLER

A dissertation submitted in partial fulfillment of the requirements for the degree of

DOCTOR OF EDUCATION

Portland State University

1987 
TO THE OFFICE OF GRADUATE STUDIES AND RESEARCH:

The members of the Committee approve the dissertation of Curtis Alan Miller presented on April 14, 1987.

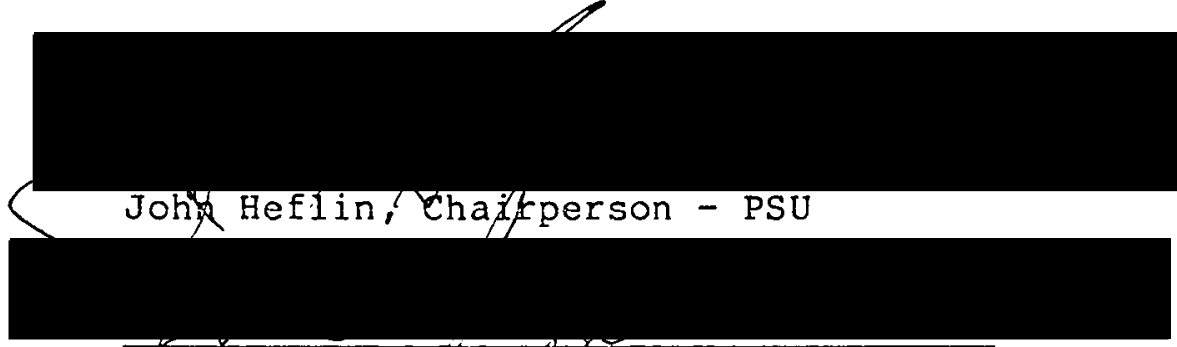

Dave Capuzzi $/$ PSU

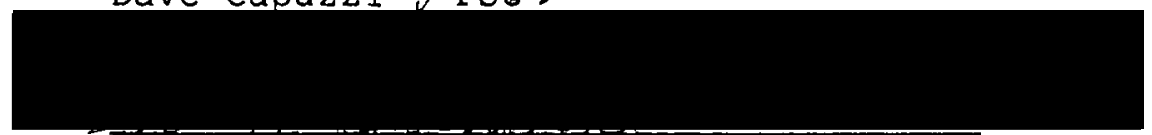

Jerry/Lansdowne - PSU

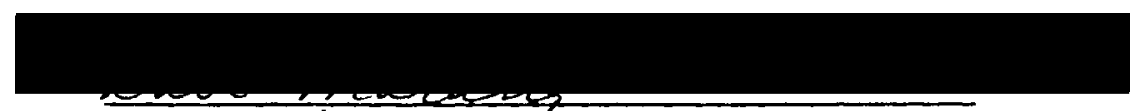

Dave Martinez-PSU

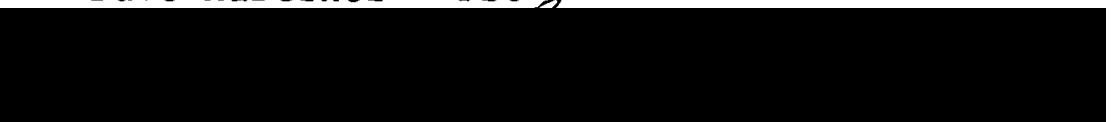

Daniel O'Toole - PSU

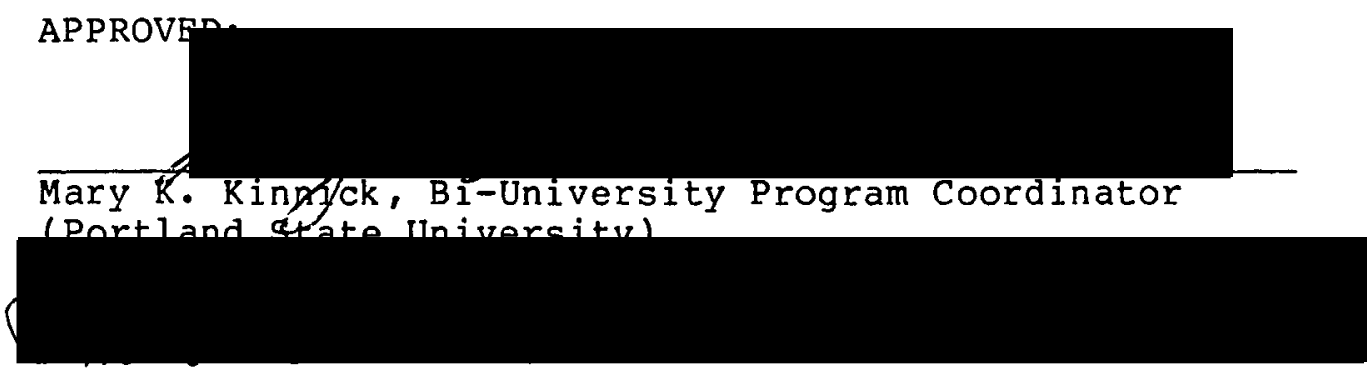

Richard A. Schmuck, Bi-University Program Coordinator (University of Oregon)

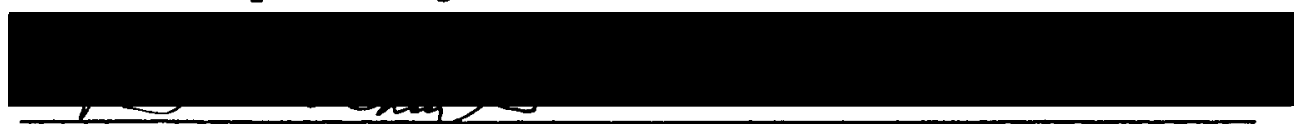

Robert B. Everhart, Dean of the School of Education (Portland State University)

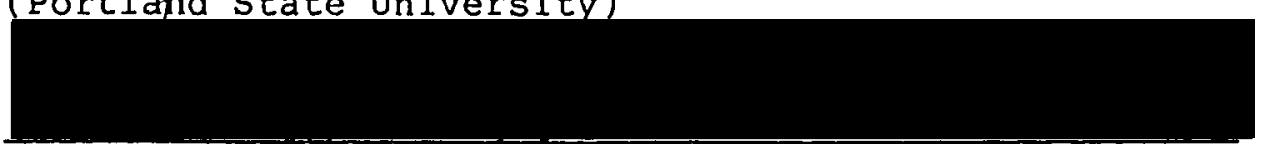

Bernard Ross, Dean of Graduate Studies and Research (Portland State University) 
AN ABSTRACT OF THE DISSERTATION OF Curtis A. Miller for the Doctor of Education in Public School Administration and Supervision presented on April 14, 1987.

Title: An Analysis of a Washington State Policy on the Appraisal of School Administrators by Certificated Subordinates.
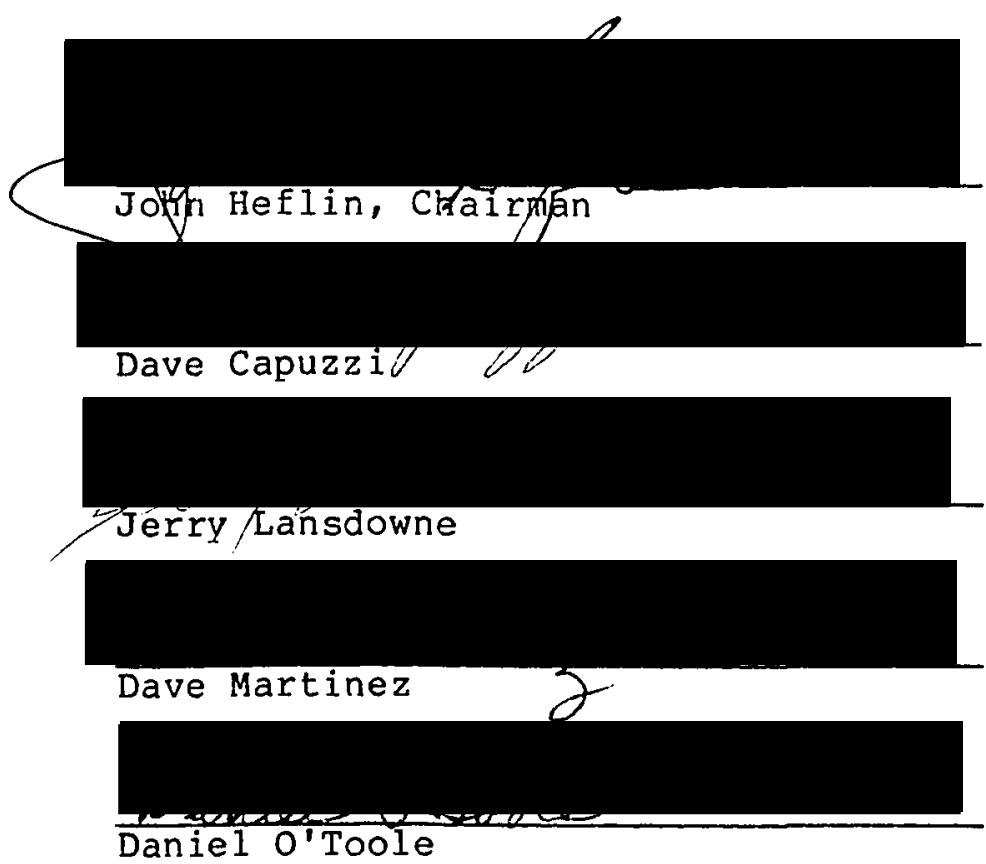

The study of the policy process can provide insights into how educational policies are implemented and evaluated. The policy process incorporates the four stage process of policy formulation, adoption, implementation, and evaluation. The present study examined the implementation and evaluation of a Washington state policy which requires that school 
administrators give their subordinates the opportunity to appraise their performance. The importance of this topic is suggested by research findings that indicate appraisals of principals by teachers yield information to assess and improve the administrative skills of principals.

Research questions sought information on activities at the state level which served to promote implementation of the state policy. Other research questions sought information on the extent and impact of local school district policies and practices that were consistent with the state policy.

The methodology for the study combined survey research and interviews. The interview methodology was used to collect qualitative information on the efforts of officials at the state level to promote local implementation of the state policy. Mailed surveys were used to collect data on the extent and impact of local school district policies and practices consistent with the state policy.

The results of this study showed that none of the officials interviewed cited any activities at the state level, which promoted the implementation of the state policy. Results of the mailed surveys indicated that only 78 of local school districts had adopted policies on appraisal by subordinates that included the require- 
ments of the state policy. Moreover, only 228 to 298 of school administrators were found to have complied with the requirements of the state policy by giving their subordinates the opportunity to appraise their performance. School personnel in a position to evaluate the effects of appraisal strategies reported that these strategies were beneficial for assessing administrator performance. Some school personnel also reported improvements in administrator performance and the school program, as a result of these appraisal activities. However, elements of the strategy described in state policy neither ensure changes in administrative behavior, nor protect subordinates against reprisals for making the appraisal.

The evaluation of the state policy suggests that the continuation of this policy will enable school personnel to reap the benefits of appraisal by subordinates. However, the policy should be modified to reduce the impact of problems associated with the procedure specified in policy. Regardless of the appraisal procedure used, interest group support must be strong enough to insure widespread implementation of policies promoting appraisal by subordinates. 
ACKNONLEDGMENTS

I wish to express my sincere thanks to the members of my dissertation committee for their assistance in the development of this study. Special mention must be made of John Heflin, whose guidance was invaluable in helping me shape an idea into the reality of this dissertation. I would also like to thank Daniel o'Toole and Jerry Lansdowne for providing their expertise in public policy analysis. Dave Martinez has my appreciation for encouraging my efforts in the doctoral program. Finally, I would like to express my gratitude to Dave Capuzzi for his very helpful and friendly guidance throughout my doctoral studies. 
TABLE OF CONTENTS

PAGE

ACKNOWLEDGMENTS........................ i i

LIST OF TABLES....................... viii

CHAPTER

I INTRODUCTION..................... 1

A Conceptual Basis for the Research

Questions....................

2

Background Information on the Research

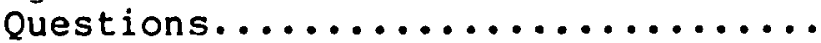

4

Problem Identification

Policy Formulation

Legitimation of the Policy

Policy Implementation and Evaluation

Statement of the Research Questions.... 11

Importance of the Research Questions... 14

I I REVIEW OF THE LITERATURE............. 18

Policy Analysis in Education.......... 20

An Historical Perspective on the Study of Politics in Education

Conceptual Models for the Analysis of Public Policies

Research Directions in Educational Policy Analysis

Research Methods for the Study of Policy Implementation and Evaluation

Empirical Findings on the Character of the Policy Process 
Governmental Institutions Responsible for Education in the State of Washington Summary

The Appraisal of School Administrators..

Goals of Administrator Appraisal

Current Status of Administrator Appraisal

Sources of Information for Administrator Appraisal

Support for Teacher Appraisa 1 of School Administrators from Organizational Theory

Support for the Appraisal of School Administrators by Subordinates from Leadership Theory

Empirical Support for Teacher Appraisal of Administrators

Disadvantages of Appraisal by Subordinates

Summary of Research on the Appraisal of School Administrators by Subordinates

Summary of the Literature Review and statement of the Research Questions..

Summary of the Literature Review Statement of the Research Questions

I I METHODS ........................

Methodology for Research Question One on

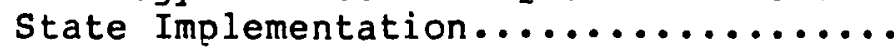

Subjects

Instruments

Procedure

Methodology for Research Questions Two Through Five on Local Policy Adoption, Implementation, and Evaluation........

Methodology for Research Question Two on Local Policy Adoption 
Methodology for Research Questions Three Through Five on Strategy Implementation and Evaluation

Summary of Method................ 92

IV $\operatorname{RESULTS\ldots \ldots \ldots \ldots \ldots \ldots \ldots \ldots \ldots \ldots \ldots \ldots \ldots .\ldots \ldots } 93$

Interviews of state Level officials Providing Qualitative Information on State Level Implementation.........

Policy Implementation

Factors Contributing to Policy Implementation

Quantitative Data from the Survey of School District Policies.......... 101

Quantitative and Qualitative Information Collected from Surveys of Local School District Personnel..

Rates of Response to Mailed Surveys Quantitative Information on Opportunity to Appraise

A Comparison of Opportunity to Appraise with Actual Appraisal Qualitative Data on Reasons for Appraisal by Subordinates Qualitative Information for the Evaluation of Strategy Impact Sumnary of Results

Policy Implementation at the state

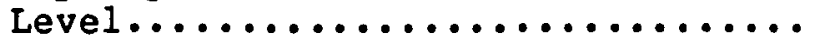

Analysis of State Level

Implementation

Analysis of Data with Models of Policy Analysis

Local Implementation of the Appraisal

Strategy..................... 
Rates of Response to Mailed Surveys

Local School District Policy Adoption

Strategy Implementation: The Opportunity to Appraise

Reasons for Appraisal

Policy Evaluation: An Evaluation of

Appraisal Activities Meeting the

Requirements of State Policy........

Attribution of Impact

Benefits of Appraisal Activities

Problems with Appraisal Activities

Conclusion

Summary of Discussion............ 150

VI CONCLUSION....................... 152

Addressing the Research Problem....... 152

Implications for Policy-Making....... 157

Implications for Educational Practice.. 161

The Need for Appraisal

Modification of Policy Requirements

Methodological Problems............ 166

Directions for Future Research....... 169

Summary of Conclusions............ 172

REFERENCES............................ 176

APPENDICES............................. 185

Appendix A: Format for the Interviews of State Government and Professional Association

Officials......................... 185

Appendix B: Survey of Local School Districts

and Cover Letter..................... 187

Appendix C: Survey of Middle Level School

Administrators and Cover Letter........... 189 


\section{LIST OF TABLES}

TABLE

PAGE

I Response Rates of School District

Personnel..................... 103

I I Rates of Opportunity to Appraise......... 105

II Reasons for Appraisal Practices

Consistent with State Policy......... 109

IV Superintendent Reported Benefits and

Problems with the Strategy of

Appraisal by Subordinates........... 110

$V$ Middle Level Administrator Reported

Benefits and Problems with the

Strategy of Appraisal by Subordinates.. 112

VI Teacher and Support staff Reported

Benefits and Problems with the

Strategy of Appraisal by Subordinates.. $\quad 114$

VII Relationships between Policy Issues and the Results of this study........... 153 


\section{CHAPTER I}

\section{INTRODUCTION}

This is a study of 1 aw and government in washington public education. Specifically, it is an analysis of a state policy for local education agency (LEA) administrator evaluations by subordinates. The objectives of this study are as follows:

1. Present an examination of the policy formulation process;

2. Analyze the processes, instruments, and dynamics of the policy implementation process; and

3. Assess the effects of the state policy on the improvement of administrative behavior.

When analyzing the actions of governments, political scientists frequently adopt the "public policy process" as a conceptual framework. In studying the policy process, political scientists study what policies governmental units pursue, why they pursue these policies, and the consequences of pursuing these policies (Dye, 1981). In the present study, policy will be defined as rules which reflect the public interest (Dewey, 1947).

The current study will examine a Washington state 
policy using the public policy process model. Developed in 1976 , this policy requires that certificated subordinates in public schools be given the opportunity to appraise their immediate supervisors. The specific focus of this study is the implementation of the policy by state and local education personnel. The state policy will also be evaluated to determine whether the implementation of the strategy described in the state policy resulted in effects intended by policy-makers.

A CONCEPTUAL BASIS FOR THE RESEARCH QUESTIONS

The public policy process model serves as a framework for the development of the research questions in the present study. In order to provide better understanding of how the research questions were developed, a brief overview of this model is necessary. The following description of the public policy process model represents only an outline of this model. A more thorough description of this model is presented in Chapter II, The Review of the Iiterature.

According to Dye (1981), the process model was developed by political scientists, who studied the activities of participants in political systems to discover recurring patterns to these activities. From a study of 
these activities, a common pattern of policy development emerged. Dye identified five elements in this pattern. The first stage in this process is the identification of the problem. After problems are identified, policy proposals are formulated. At the second stage in the process of policy development, policy formulation involves the development of alternatives to solve the problem. The third step in the process of policy development is the legitimation of policies. Policies are legitimated by the selection of a proposal by a governmental unit and the adoption of the proposal as law. The fourth step in the policy process is the implementation phase. The implementation of policies involves the response of governmental bureaucracies in a manner prescribed by law. This response may include the provision of services or funds or may involve the enforcement of regulations. The fifth and final phase of the policy process is the evaluation of policies. As described by Dye, the evaluation of policies may include the study of outcomes associated with a particular policy. Based upon this study, the evaluation may include recommendations for the continuation, revision, or termination of policies.

The paradigm, the public policy process model, governs the direction of the study of policy by serving a number of important functions. The functions of a para- 
digm can include:

1) the provision of a conceptual Eramework, 2) the selection of the problems which are critical at any point and time, 3 ) the identification of the appropriate research methodology and instrumentation, and 4) the definition of legitimate empirical phenomena that will be accepted as evidence (Kuhn, 1970).

BACKGROUND INEORMATION ON THE RESEARCH QUESTIONS

The present study will focus on the implementation and evaluation stages of the policy process for the state policy on appraisal of school administrators by subordinates. To better understand the implementation and evaluation stages of the policy process, an outline is needed of the three prior stages of the policy development process (problem identification, policy formulation, legitimation). With the respect to the state policy on appraisal by subordinates, the following sources failed to yield an integrated description of the first three stages of the policy process: 1) a review of current professional literature in education, 2) an interview of an education committee staff coordinator in the state legislature, and 3 ) records from the proceedings of the Washington State Legislature. Because of the limited information on policy development, the reconstruction of the first three phases of the policy process will require 
a degree of conjecture.

\section{Problem Identification}

At the first step of the policy process, the identification of the problem necessitates consideration of the political climate in American public education in the years prior to 1976. During the 1960 s and 1970 s, public schools were under attack from the citizenry for failing to provide an education of adequate quality. Concurrent with the attack on the quality of public education, personnel responsible for the administration of the public schools were also subjected to criticism. Certain arguments advanced at this time called for actions to insure that the performance of school administrators was maintained at a high level. At the first stage in the development of the state policy on appraisal by subordinates, the problem may be identified as follows: How can the performance of public school administrators be improved?

\section{Policy Formulation}

At the second phase of the policy process, state legislatures responded to the problem by developing proposals to improve the performance of school administrators. These proposals included the development of pro- 
cedures for the evaluation of the performance of these school personnel. Proposals were formulated for who should appraise the performance of school administrators and how the appraisal should be done.

Traditionally, the evaluation of school administrators has been the responsibility of their supervisors. However, some educators have argued that the subordinates of school administrators can help administrators improve their professional performance. Therefore, proposals for addressing the problem of improving the performance of school administrators included proposals for evaluation by superiors and proposals for appraisal by subordinates.

\section{Legitimation of the Policy}

At the third phase of the policy process, most state legislatures adopted laws requiring the evaluation of school administrators by their superiors. Apparently realizing that subordinates can have valuable appraisal information for their supervisors, the Washington State Legislature adopted a law providing for the appraisal of school administrators by their subordinates.

A review of journals and tapes of legislative hearings and floor debate provided information on the adoption of the state policy on the appraisal of school administrators by subordinates. The provision requiring 
that certificated subordinates be given the opportunity to appraise school administrators was added to Washington state statutes in 1976. The provision was adopted by the Senate Education Committee as an amendment to House Bill 1364, legislation on teacher and administrator evaluation. After a review of the House and senate records, Reinert (1985) was unable to find any reference to this provision in debate or discussions on the floors of the House and Senate. A review of Senate Education Committee hearings on House Bill 1364 similarly revealed that testimony centered on the issues of probationary period duration and appeals of dismissals. No reference was made to the provision of appraisal of school administrators by their certificated subordinates. Therefore, the provision was entered into statute without public debate or discussion. Moreover, no funding was provided to implement the state policy. The provision is as follows:

(3) Each certificated (school) employee shall have the opportunity for confidential conferences with his or her immediate supervisor on no less than two occasions in each school year. Such confidential conference shall have as its sole purpose the aiding of the administrator in his/her professional performance (Revised Code of Washington (RCW) 28A.67.066(3)).

Clarification of Terms. Several assertions are necessary in order to more clearly define terminology to be used in reference to the preceding Washington state 
policy. The Washington state policy includes a goal and a strategy for reaching that goal. The goal is to achieve and maintain quality school administration. In the present study, the strategy for potentially reaching this goal is subordinate appraisal of school administrators. This strategy can include the following elements: 1) the certificated subordinate's observations of administrator performance, 2) value judgments as to the adequacy of the administrator's performance, possibly leading to 3 ) the subordinate's suggestions to the administrator to improve administrative performance.

The formulator and implementor of the state policy are the Washington State Legislature and state education agency, respectively. The implementors of the strategy described in the state policy are school administrators in the State of Washington. School administrators include superintendents of schools, principals, and special education administrators. Other personnel of interest in this study include teachers and certificated support personnel.

Inferring Policy Intent. Duane Slate, Staff Coordinator for the Senate Education Committee, reported that the state policy on appraisal by subordinates was a part of the School Personnel Evaluation Statute. The purpose of this statute was to assure the public of the 
quality of public school personnel (Slate, 1986). Slate indicated that teacher groups saw the statute as being "anti-teacher." He observed that the policy providing for appraisal by subordinates represented an attempt to dispel the "anti-teacher" image of the statute. He reported that teacher groups advocated the adoption of the policy on appraisal by subordinates. Slate also reported that administrator groups were not opposed to this proposal, as they acknowledged that administrators could improve their skills in evaluating teaching personnel. Slate could not recall the names of any specific individuals advocating or opposing this policy.

slate reported that the intent of the policy was to limit teacher suggestions to how the supervisor could better help the teacher meet professional work goals. Slate saw the intent of the state policy as directed toward improving the administrator's evaluation of the teacher, rather than being oriented toward improving all aspects of the administrator's performance. Supporting this contention, Slate noted that the state policy was within the context of a teacher evaluation statute. Therefore, slate perceived the intent of the state policy as being a way that a teacher could seek the assistance of the administrator to meet performance goals defined in the teacher's evaluation conference. 
If Slate's contention is accepted, the scope of the state policy would be somewhat restricted. However, his contention can be brought into question for several reasons. First, the contrast between the broadly worded state policy and Slate's narrow interpretation of the policy must be questioned. If the legislature had intended the narrow purpose for the state policy advanced by slate, then the policy could have been worded to limit the teacher's appraisal to the administrator's evaluation of the teacher. However, the policy broadly states that the subordinate has the opportunity to assist the administrator in his/her professional growth. Secondly, slate supports his interpretation by noting that the state policy was within a teacher evaluation statute. However, the state policy is actually within a statute that mandates the evaluation of all certificated school employees, not just teachers. The policy is within a section specifying requirements of administrator evaluation. Therefore, Slate's interpretation of policy intent can be regarded as debatable.

Indeed, the interpretation of the breadth of this policy may need to be decided by Attorney General opinions or litigation. While the breadth of this state policy is equivocal, the policy can be regarded as allowing for the appraisal of at least some aspects of admin- 
istrative performance. As either interpretation acknowledges that the policy provides for the appraisal of administrator performance, the implementation and impact of the state policy can be assessed.

\section{Policy Implementation and Evaluation}

At the fourth and fifth stages of the policy process, the policy is implemented and evaluated. However, Dye (1981) has observed that the adoption of a policy does not insure that the policy will be implemented. Moreover, the implementation of a policy does not insure that the policy will result in the effects intended by policy-makers (Jones, 1984). From a review of published professional education literature and legislative records, no research has been found that has studied the implementation or evaluated the effects of the Washington state policy on appraisal of school administrators by subordinates. Therefore, the research questions of the present study address the implementation and evaluation of the state policy.

\section{STATEMENT OF THE RESEARCH QUESTIONS}

The first research question of this study is associated with policy implementation by educational person- 
nel at the state level. Policy implementation involves activities by state level officials to insure that the strategy described in the legislative policy is carried out at the local level. Educational personnel of interest at the state level will include personnel at the state education agency (SEA), education committee staff persons in the legislature, and representatives of professional associations. The first research question is as follows:

What actions were taken by educational personnel at the state level to insure that the state policy on the appraisal of school administrators by subordinates was implemented by local school districts and school administrators?

The second through fourth research questions assess activities at local school district levels that promote implementation of the appraisal strategy described in state policy. To assist in the implementation of state policies, local school districts can adopt policies, which direct school administrators in the district to carry out state policy directives. The second research question addresses this activity and is stated as follows:

To what extent have policies been adopted by local school districts in conformance with the state policy on the appraisal of school administrators by certificated subordinates?

The third research question relates to the actual 
implementation of the strategy described in state policy by local school administrators. Past studies of administrator appraisal have found that some school administrators support the strategy of appraisal of administrators by teachers. However, a review of the literature failed to reveal research studies that have assessed the extent to which school administrators are providing their subordinates the opportunity to appraise administrator performance. The third research question will provide empirical information on the frequency of this activity. Therefore, the third research question is as follows:

To what extent have school administrators given their subordinates the opportunity to appraise their administrative performance pursuant to state policy?

The fourth research question addresses the problem of whether subordinates actually appraise their supervisor's performance, when given the opportunity. The fourth problem is stated as follows:

When given the opportunity to appraise their supervisor's performance, to what extent do certificated subordinates actually choose to appraise their supervisor's performance?

The fourth research question will provide information on whether the impact of the state policy can be attributed to 1) the opportunity to appraise or 2) the opportunity to appraise and the appraisal, itself. This research question is directed to determining the extent of ap- 
praisal by subordinates that is consistent with state policy

The final research question to be studied relates to the evaluation of the impact of the state policy. Information derived from this question may provide data on whether the state policy should be continued, revised, or terminated. The fifth research question is stated as follows:

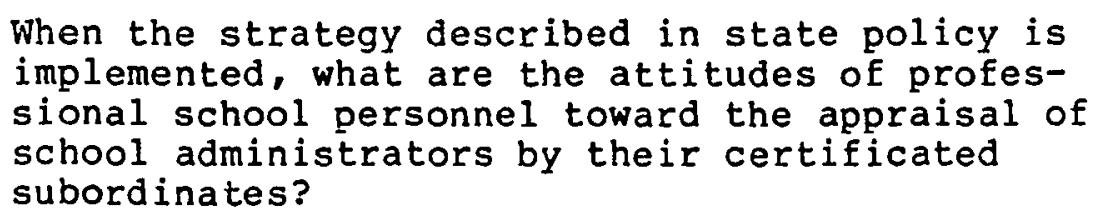

THE IMPORTANCE OF THE RESFARCH QUESTIONS

Sapone (1981) reports that public demand for educational and fiscal accountability has increased greatly in recent years. In order to receive public approval of additional tax revenues for schools, the public's confidence in education must be restored. Zakrajsek (1979) believes that school personnel must prove to the public that they are accountable for devoting sufficient skills and effort in the educational process. Featherstone and Romano (1977) assert that an effective appraisal system for teachers and administrators can accurately assess the talent and efforts of school personnel. 
Mann (1985) has noted that recent reforms in public education have focused on the improvement of teachers. Mann has observed that these reforms have largely ignored the improvement of principal, even though the principal may play a primary role in improving the quality of education in the public schools.

Some writers believe that appraisals may be more important to administrators than to teachers for several reasons. First, administrators' duties are not as welldefined or observable as teachers'. Second, the appraisal of administrators may be more important, because principals can be more readily fired or reassigned, if their performance is inadequate (Deal, Dornbusch, \& Crawford, 1977).

Hunt and Buser (1977) have reported that teachers are a major force calling for administrator accountability. Because teachers are being forced to account for their productivity, teachers are demanding that administrators be appraised. Moreover, teachers are demanding the opportunity to provide input into these appraisals. Recognizing the value of administrator appraisal for the improvement of public education, it is important to determine how the Washington state policy on administrator appraisal has been implemented by state education agency (SEA) bureaucrats and local school administrators. 
It is aiso important to evaluate the state policy to determine whether the policy achieved its intended effects of improved administrator performance.

Regarding the importance of the first problem of this study, the examination of the implementation of this state policy may provide information on the the procedures by which the content of the state policy on administrator appraisal was communicated to local school administrators. This information may elucidate relations among educational professional associations and state governmental units responsible for public education in the state of Washington. The second and third problems will assess the effectiveness of the SEA and local school districts in insuring the implementation of the strategy specified in state policy by local school administrators. This information may also clarify the relations between the SEA and local school districts with regard to the implementation of policies governing the evaluation of school personnel. The fourth and fifth problems are designed to address the issue of whether the goal of improved administrator performance has been realized by the implementation of the strategy described in state policy. If school personnel report that the strategy has been implemented, then the strategy may be evaluated as to whether its implementation has resulted in improved 
administrator performance. If the implemented strategy has resulted in improved administrator performance, then the state policy should probably be continued. If the strategy has failed to achieve desirabie effects, then the state policy should be modified or terminated, so that more effective methods can be specified to improve administrator performance.

It is anticipated that the present study will serve as a definitive study on the nature and extent of the implementation of the Washington state policy on appraisal by subordinates. With regard to the general practice of appraisal by subordinates, the present study will serve as exploratory research on the extent and effects this general practice. It is an exploratory study on this general practice, because its scope is limited to one type of strategy of appraisal by subordinates. Even though this study is restricted to the study of a specific strategy of appraisal by subordinates, the findings should provide preliminary data on how extensively appraisal by subordinates is undertaken in the public schools. Additionally, the present study may provide tentative conclusions on the usefulness of appraisal by subordinates for the improvement of school leadership. 
CHAPTER II

REVIEW OF THE LITERATURE

The purpose of this chapter is to provide an indepth description of professional literature relevant to the research problem. By describing research methodologies, theories, and empirical findings in the professional literature; relations can be established between elements in the professional literature and the research problem. These relations serve as the basis from which research questions and methods used in the present study were developed. This chapter will also serve the purpose of describing information that will assist in the interpretation of the results of this study.

More specifically, the review of topical areas in the fields of political science and educational administration will provide a context for the study of the Washington state policy on administrator evaluation. In relation to political science, theoretical models used in the analysis of public policies will be reviewed. An overview will address goals and methods of policy research. Problems with the implementation of policies by 
governmental institutions will be described. Greater detail on state policy implementation will be provided by a review of research on relations between state and local agencies responsible for the administration of public education. Next, the governance and administration of education in the State of Washington will be outlined. From a review of these topics, background information will be provided on research questions related to state policy and strategy implementation (research questions $1-3)$

In relation to educational administration, topics relevant to administrator evaluation will be presented. From a review of professional 1 iterature, the goals and current status of administrator appraisal in the public schools will be summarized. While an exhaustive roview of administrator evaluation will not be attempted, a thorough review on the appraisal of school administrators by subordinates will be presented. A basis for understanding appraisal by subordinates will be provided by reviewing theoretical propositions and empirical findings on teacher appraisals of principals. By reviewing literature on appraisal by subordinates, background information will be provided for the evaluation of the state policy on appraisal by subordinates (research questions 4 $\& 5)$. 
POLICY ANALYSIS IN EDUCATION

In Chapter I of this paper, the importance of appraisals of school administrators by their subordinates was briefly outlined. If appraisals of school administrators by subordinates can serve to improve administrator performance, what actions can be taken to insure that administrators solicit input from their subordinates? One way to increase the likelihood that administrators will seek such input is to require appraisals by subordinates in public policy. By requiring this practice in public policy, governmental incentives and sanctions can be employed to insure that this activity is carried out. This section will provide a basis for understanding public policy by providing an overview of the study of politics in education. In this overview, a description of conceptual models, research methods, and empirical findings relating to the analysis of public policies will be provided.

An Historical Perspective on the Study of the Politics in Education

Elliot (1959) authored the one of the first widely recognized articles advocating the study of political 
phenomenon in public education. Contrary to an earlier anti-political doctrine espoused by professional educators, Elliot asserted that public schools are political entities and are appropriate subjects for study by political scientists. At that time, Elliot recognized that professionals in public education advocated the continuation of a closed system of politics in American public education. This closed system was characterized by isolation from other political units, a slow rate of internal change, and restriction of research on the politics of the educational system (Iannaccone, 1967; Kirst and Mosher, 1969).

However, the political environment of the public schools changed dramatically in the mid-1960s. The governance of the public schools became increasingly politicized for a number of reasons, such as:

1. increased competition for funds from social programs,

2. reduced approval of property tax levies for school support, 3. greater involvement in the schools by lay interest groups,

4. federal aid legislation requiring community advisory committees,

5. the search for more equitable financing for school programs, and

6. the demand for evaluation and accountability (Boyan, 1981; Cistone, 1976; Kirst and Mosher, 1969; Mosher, 1980).

Conflict and competition among lay and professional groups resulted in greater political pressure being 
placed upon decision-makers. In this fast changing political environment, a need arose for educators to exhibit greater competence in evaluating political forces when developing, implementing, and evaluating educational policies (Cistone, 1976). The development of this competence required the construction of a theoretical base and research methods to study political interactions. By the end of the $1960 \mathrm{~s}$, many educators came to agree with Elliot's earlier contentions that 1) public policy in education is the product of professional-lay interactions at different governmental levels and 2 ) the study of these interactions can lead to more productive educational leadership. However, as Kirst (1970) would lament, lack of theory and methods would pose difficulties for the researcher in the politics of education. Even though research inquiry in educational administration can involve "the use of one of several highly specialized conceptual lenses" (Boyan, 1981, p. 7), wirt (1979) has advocated the selection of educational policy analysis as the primary domain for research and training in educational administration. Policy analysis was defined by Boyd and Immegart (1979) as "the study of the causes and the consequences of policy differences at all levels of the educational infrastructuren (p. 277). For Wirt, a primary advantage of policy analysis research was 
the possibility of meeting the practical needs of the educational administrators in the schools, in addition to satisfying "the intellectual interests of scholars of educational administration" (p. 11).

Agreeing with Wirt's call for the primacy of policy analysis, Boyd and Immegart (1979) favored study in this domain because of the possibility of synthesizing theory and practice, as well as unifying research from different fields of study. However, Boyan (1981) has recognized that policy analysis may not be acceptable to some scholars of educational administration, because of the strong reliance of this paradigm on social and political demands for immediate consequences.

Therefore, the study of the politics of education is a relatively recent development in educational administration. The analysis of educational policies is fast becoming a popular research paradigm, which integrates the immediate pragmatic concerns of the practitioner with the scholarly pursuits of the scientist.

Conceptual Models for the Analysis of Public Policies

A number of models have been formulated to describe, explain, and sometimes predict political phenomena. Researchers use these conceptual models to generate research hypotheses and guide the analysis of public 
policies. Each conceptual model provides a different perspective on what governments choose to do or choose not to do (public policy), why they do it, and the consequences of pursuing a particular policy (Dye, 1981).

The Rational Model and Game Theory. Dye identified eight models that can be used for conceptualizing political behavior. The first two models, the rational model and game theory, are theoretical frameworks that include the assumption of rational decision-making by policy makers.

The rational model assumes that a rational public policy is one that maximizes the attainment of societal goals, while simultaneously minimizing the sacrifice of other societal goals. The rational model assumes that all societal goals, policy alternatives, and policy consequences are knowable. Once these contingencies are known, this model further assumes that a ratio of achieved versus sacrificed goals can be calculated for each policy alternative. The policy selected can include the best ratio of achieved to sacrificed goals (Dye, 1981).

Game theory is an application of the rational model to competitive situations. Game theorists conceive of many public policy decisions as being compromises between conflicting interests (Mood, 1983). More specifically,

game theory serves as an analytic tool for situations where outcomes are dependent upon participants' actions. Each participant in the situation must predict the actions of their opponents from an analysis of their opponents' values. Based upon a prediction of the opponents' actions, a strategy can be devised to achieve a particular outcome which will maxim- 
ize gain and minimize loss for the participant (Dye, 1981).

Hamburger (1979) describes the task of the game theorist to identify the primary decision-makers and significant decisions to be addressed. Next, the possible consequences of each solution are identified and analyzed in terms desirability to each of the players. Hamburger has identified a set of concepts termed, "principles of rationality", that can guide players to preferred outcomes.

However, Hamburger (1979) acknowledges that the rational strategy of policy-making is frequently based upon the false assumption that "people are clever enough to think through full interactive consequences of their actions" (p. 249). Therefore, while the game and rational models provide descriptions of how institutions should ideally function, they fail to conceptualize how institutions function in actuality. This failure is due to constraints on rational decision-making in governmental institutions (i.e., insufficient knowledge of all societal goals, policy alternatives, and policy consequences) (Van de Ven, 1983). Van de Ven also observes that the rational model also fails to acknowledge the importance of values and moral issues in policy-making. Mood believes that the game model is seldom able to find expli- 
cit solutions, because conflicts are based upon value judgments, which cannot easily be put into quantitative terms.

Nevertheless, Mood (1983) asserts that game theory is useful to policy-makers for placing conflict into rational context. Game theory also provides a rational context for the development of compromises. While the rational theory proposes to guide the governmental unit toward the efficient achievement of societal goals and values, the theory is more useful in helping to identify barriers to rationality. Ironically, it helps the student of public policy realize the extent of and reasons for irrationality in governmental decision-making (Dye, $1981)$

In relation to the present study, the rational model may be used to identify irrationalities in the process of policy implementation by asking the question,

"What factors impair the implementation of state policy as designed?" Game theory may have usefulness in the evaluation stage of the policy process. This theory might assist in the development of policy alternatives to increase support or decrease opposition to modifications of existing policy.

Incremental Model. The incremental model represents a response to the limitations of the rational model 
(Dye, 1981).

Lindblom (1959) recognized that because of constraints of time, information, cost; governmental decision-makers are unable to regularly review the entire range of policy alternatives and their potential consequences. Instead, public policy is viewed as a continuation of past governmental activities with only incremental modifications (deletions and additions) of past policies. Risk-taking is kept to a minimum by making only slight changes in past policies, thus keeping unanticipated consequences to a minimum. Only a limited number of policy alternatives are considered at a time and a few important policy consequences are evaluated. Lindblom observes that problems to be addressed by the policy-maker are being continually redefined by many incremental policy adjustments. Incremental policy-making is oriented toward solution of present, concrete problems, rather than the advancement of future goals.

Etzioni (1973) contends that the incremental model does not comprehensively describe actual policy-making. He notes that organizations sometimes make major changes in basic policies. These major changes are responses to pressures and changes inside and outside the organization. Etzioni believes that incremental decisions frequently occur in a series following a major policy decision to "fine tune" the major decision.

In relation to the present study, the incremental model may serve to explain difficulties in implementing the state policy on appraisal by subordinates by state and local administrators. To the degree that the state policy represents a major deviation from prior policies, 
difficulties in implementing this initiative may be explainable, at least in part, by the incremental model.

Institutional Mode1. According to Dye (1981),

the institutional model focuses on the systematic relationships between institutional arrangements and the content of public policy. This model is based upon the premise that governmental institutions may be structured to facilitate implementation of some policy alternatives, while interfering with others. Institutional studies have traditionally involved descriptions of governmental institutions. E1ements of interest included the institution's structural organization, duties, and functions.

This model assumes that the nature of institutional arrangements affects the content and impact of public policy. However, Dye contends that changes in institutional arrangements may not necessarily change public policy; if relevant social, economic, and political forces in the environment remain constant.

The institution is important to public policy, because public policy is formulated and implemented within institutional contexts (Hall and Quinn, 1983). When implementing policies, the institution has traditionally been considered a "black box" (Beyer, Stevens, and Trice, 1983). This "black box" view assumes that the policy is implemented by the institution in the same manner intended by policy-makers. In actuality, the policy can undergo a great many changes during implementation.

Because the institution influences and is influenced by other institutions, increased interest has been directed toward the study of interorganizational rela- 
tionships (Hall and Quinn, 1983). Rainey and Milward (1983) suggest that the study of vertical and horizontal interactions across governmental agencies and outside agency boundaries may be a fruitful line of policy research.

Barton (1961) has described a framework for the study of the internal and external characteristics of institutions. External characteristics can include 1) inputs (i.e., economic resources), 2) outputs (i.e., the consequences of its activities), and 3) the relationships among the institution, other organizations, and the general public. Internal institutional characteristics include the institution's 1) social structure (i.e., formal authority structure), 2) attitudes (i.e., organizational goals), and 3 ) activities (i.e., individual role behavior).

Within the context of educational policy analysis, examples of the use of the institutional model have included Bailey and Mosher's (1968) study of the Eormulation and implementation of Title I requirements by administrators at federal, state, and local levels. More recently, Thomas (1975) described the influence of institutions within the federal bureaucracy on the development of education policies in the 90 th Congress.

In conclusion, Kirst (1970) has recognized the need 
to explore the interactions between the various levels and branches of government in education. As Hall and Quinn (1983) note, "public policy cannot be understood without a consideration of the implementing organization" (p. 15). In relation to the present study, an investigation of the institutions responsible for educational policy is essential for understanding the governmental institutions' implementation of the state policy on the appraisal of school administrators by subordinates. The institutional model may have relevance in the present study as relationships among state level institutions and communication linkages across state and local levels are examined. These relationships and linkages will be discussed in greater detail later in this review, when professional literature on the relations between state and local education agencies are described. Group Theory and the Elite Model. Dye (1981) has observed

group theory and the elite model both focus on the power of organized groups in influencing public policy. In group theory, public policy is viewed as reflecting the relative influence of competing interest groups at a given time. Government is viewed as managing conflict between competing groups by establishing rules, arranging compromises in the form of public policies, and enforcing these compromises.

Frohock (1979) has asserted that an interest group is any group with shared attitudes that makes claims on 
other groups. These claims promote behaviors related to an interest group's shared attitudes. Frequently, interest groups are formed, when external pressures threaten values or behaviors associated with their shared attitudes. Within the context of competing interests, compromise between groups is the typical resolution of conflicts (Frohock, 1979). However, Hanson (1979) notes that in some cases compromise may be unplanned or even unwanted.

While group theory focuses on group struggle, Dye

(1981) has described

the elite model as stressing the influence of a
few individuals largely from the upper socio-
economic class. In the elite model, it is
asserted that public policy reflects the values
of a small group of elite individuals, This
group of elites 1 ) share the basic values of
the social system (i.e. limited government,
private property, individual liberty) and 2 )
recognize the importance of the preservation of
the social system and their position within it.
The values of this elite group are carried out
by public officials and shape the opinions of
the masses.

In the group model, the political system is viewed as being a lateral system of unranked interest groups making demands upon each other. In the elite model, the political system is viewed as being vertically ranked in terms of effectiveness, prestige, or wealth. The socially superior elite governs society in the elite model (Frohock, 1979). 
In the present study, group theory and the elite model may be critical to the implementation and evaluation of the state policy on appraisal of school administrators by subordinates. This assertion is based upon the importance of the power of elites and interest groups in promoting the implementation of state policies.

Systems and Process Models. As outlined by Dye (1981), the process model and systems theory both attempt to identify sequential patterns for the analysis of public policies. These models are based upon the recognition that the legislative process involves a temporal sequence of actions (Frohock, 1979).

Using the systems model, the political system is described as "the interaction of two or more interdependent units that persist over timen (Frohock, 1979, p. 15)

Systems theory conceives of policy as a response of a political system to demands or support from the environment. The systems model include cyclical interactions of inputs, conditions, the political system, outputs, and feedback (Dye, 1981).

As Elliot (1959) observed, systems may be open or closed, depending upon the system's responsiveness to the environment. While the open system responds to the demands or stresses environment, the closed system does not. Political systems in education have been character- 
ized as becoming more open (i.e., Cistone, 1976).

In open systems theory, the interdependence between the political system and its environment is considered to be important (Hanson, 1979). The political system must respond to the demands of society to insure society's support of the political system. The strength and direction of environmental forces influence the stability of the political system.

Thompson (1976) has provided an example of systems theory applied to educational policy-making. At each level of government, Thompson specified factors he believed to be important to the educational system. These factors included: 1) groups interacting in the policy system, 2) the pattern of influence between groups in the policy system and environmental forces, 3) access of social groups to decision-makers, and 4) policy-making processes.

Katz and Kahn (1966) have stated that systems theory is not a theory in the traditional sense. They note that basic concepts of systems theory typically do not lend themselves to hypothesis testing. Instead, systems theory provides an approach and conceptual language for understanding and describing different types of political activity. In relation to the present study, the systems approach may have relevance, when considering 
the interrelationships between governmental institutions and interest groups in education and the output generated from these interrelationships.

Dye (1981) has portrayed the process model as being used to discover identifiable patterns in the activities of participants in policy development. May and Wildavsky (1978) observed that, by using the process model of policy analysis, attention is focused "upon generic activities integrally linked within the policy process" ( $p$.

10). As described in Chapter I of this paper,

The five stages of the policy-making process include 1) demands for governmental action, 2) formulation of proposals for public policies, 3 ) legitimation of policies 4) policy implementation and 5) evaluation of policies. By applying these stages to actual policy problems, the investigator can study how decisions are made and how they should be made (Dye, 1981).

Dye's description of the policy process model is very similar to process model described by other researchers (i.e., Heflin, 1981; May and Wildavsky, 1978; Jones, 1984). Relative to Dye's description, Jones (1984) provides a more detailed analysis of the policy process, prior to the policy legitimation stage. Jones observes that the following events can be important in the study of the policy process:

Within the first stage of demand for governmental action, five substages can be important in the policy process. These substages can influence the character of the demand for governmental action and affect the nature of later 
stages in the policy process. The first substage is the definition of the problem to be addressed by a particular policy proposal. The second substage is the aggregation of the demand for governmental action. Aggregation is concerned with the number of people who think the problem is important. The third substage is the demand for governmental action. This demand is described as the degree of organization of the groups who think that the problem is important. The fourth substage of the demand for governmental action is representation. Representation is defined in terms of the ways that individuals can have access to policymakers. The final substage of the demand for governmental action is how the policy proposal is placed on the agenda of policy-makers for consideration.

At the second stage of the policy process, policy formulation, Jones believes that the statement of the potential solution of the problem is critical. Additional factors to be considered in the formulation of policies include the specific policy-maker advancing this proposal and the method for advancing the proposal. In some cases, budgeting may be considered by viewing the amount and sufficiency of funding provided as a part of the policy proposal.

At the legitimation stage, Jones advocates the consideration of the supporters of the policy. The ways support for the policy is maintained can also be studied.

The implementation of the policy can be studied by viewing who administers the program designed to solve the problem. Jones also believes the modes by which program administrators maintain support may also considered.

In the policy evaluation stage of the policy process, Jones believes that the evaluation methods and persons designated for conducting the policy evaluation should be studied. The nature of policy termination or modification can be viewed in terms of what modifications have been made or how these changes were brought about.

Because the present study largely focuses on policy 
implementation, this stage requires greater attention. Implementation has been defined by Quade (1982) as being "the process of rearranging patterns of conduct so as to honor the prescriptions set forth (in policy)" (p. 305). Smith (1973) has described policy implementation as involving the interaction of four elements. These elements are the idealized policy, the target group, the implementing organization, and environmental factors. Environmental factors produce constraints on the idealized policy conceived by policy-makers. The implementing organization must direct the idealized policy through the environmental constraints to change the behavior of the target group.

Quade (1982) has noted that analysts of policy implementation have generally ignored the role of environmental factors and the implementing organization, when formulating policy. Quade recognizes the importance of developing alternative strategies to policy implementation (i.e., incentives to the implementing bureaucracy) at the formulation stage of the policy process. He notes that difficulties with implementation are likely to be encountered, whenever an external solution is imposed without the participation of those affected by the policy.

Sabatier and Mazmanian (1979) have identified five 
conditions that contribute to the implementation of a policy. These conditions include:

1) the policy is based on a valid social, political, or economic theory, which relates changes in target group behavior to the achievement of policy objectives,

2) unambiguous policy directives are specified

in statute,

3) leaders of the implementing agency are committed to the policy goals and have adequate managerial skill,

4) the policy is actively supported by organized interest groups and several key legislators, and

5) the importance of the policy is not undermined by competing policies or changes in environmental conditions.

Quade (1982) also contends that implementation of policies should avoid reliance on bureaucratic processes. Policies must also include estimates of costs of policy implementation.

As stated in the first chapter of this paper, the process model will serve to structure 1) the analysis of the research problem, 2) the development of the research questions and methodology, and 3) the presentation and discussion of the results. Because of the importance of the implementation stage of the process nodel, this stage will be described in greater detail in subsequent sections of this paper.

Conclusion. Dye contends that most public policies are not adequately conceptualized by any one of the eight models described above. Instead, a given public policy is best explained by concepts from a number of 
different models. Therefore, an actual public policy may include a combination of l) rational planning of the rational model, 2) game playing of game theory, 3) institutional influences of the institutional model, 4) incremental policymaking of the incremental model, 5) interest group activity of group theory, 6) elite preferences of elite theory, 7) political processes of the process model, and 8 ) systemic forces of systems theory.

Research Directions in Educational Policy Analysis

The preceding discussion provides background on how public policies can be conceptualized. Next, the ways that these models have been applied to the study of educational policies will be explored.

The Goals of Research. As noted previously in this chapter, policy analysis can be a potentially useful paradigm within the discipline of educational administration. Iannaccone (1972) has identified two research goals in the politics of education. The first is concerned with scholarly contributions to the knowledge base. The second research direction is directed toward questions of social need and social action.

Consistent with the research direction of social action, Heflin (1978) contends that policy research is primarily oriented toward the collection of information to guide social action. The collection of information for the development of theory may represent a secondary goal of policy research. He believes that policy re- 
search should provide "data-based guides for educational practice and decision-making at the national, state, regional and local school district levels" (p. 4). Supporting this approach, Iannaccone (1972) observed that the mere act of study is itself a social weapon and a tool in political struggles. However, Heflin (1978) recognizes that policy researchers must have a conceptual base from which to launch policy studies. Conceptual models described previously in this Chapter can provide this theoretical base. Each model provides a different focus for the study of public policy. By providing a different focus, each model may provide a different way to frame questions to guide research methods.

Forms of Research. Within the general context of educational administration, Kirst (1970) has identified three forms of research. The first form, defined by Kirst as behavioral research, is concerned with describing and explaining human behavior with empirical data collection. A second form of research has been identified as normative research. This type of research is concerned with ideal methods and ideal behavior in the field of education. Research techniques in normative research rely heavily on logic and philosophical interpretation. A third form of research, prescriptive research, is oriented toward narrowing the gap between what 
is observed and what should be attained. Prescriptive research includes both empirical observations to serve as a basis for the definition of problems and normative logic to guide research toward defined goals. As recently as 1981 , Boyan noted that the field of educational administration has previously relied on the normative research approach to describe "what ought to be." However, he observed that researchers in educational administration have been increasingly using the theoretical and methodological tools of other social sciences. Using these tools, researchers in educational administration have sought to achieve the goals of behavioral research by describing and explaining human behavior.

Summary. Social action and scholarly pursuit of knowledge have been identified as the two primary goals of policy research. In achieving these goals, research can describe actual behavior, ideal behavior, or narrow the gap between actual and ideal behavior.

Research Methods for the Study of Policy Implementation and Evaluation

To better understand the influence of political interactions on the public schools, methods for the collection of empirical information on the politics of edu- 
cation must be identified. Rirst and Mosher (1969) have noted that case studies and surveys are the most commonly used research methods in the study of the educational policy process.

Case Study Interviews. In the case study approach, the researcher attempts to conduct an in-depth study of al1 political characteristics of an institution. Interviews of those influencing and influenced by the institution are frequently obtained in case studies of political phenomena (Kirst and Mosher, 1969).

The interview methodology for collecting data has been used in prior studies of the implementation of federal policy initiatives by state education agencies. One such study was conducted by Beuke (1980). Beuke studied the implementation of the Vocational Education Act to determine the extent of state compliance with this educational policy. Beuke and his associates studied policy implementation by making on-site interviews of policy-makers, planners, and administrators in state education agencies (SEAs). Beuke used a standardized outline in conducting these interviews to allow for comparisons among interview cases. Another example of use of the interview approach was Blaschke's (1981) study of a federal law, Education For All the Handicapped Act. Blaschke assessed the extent of state level implementa- 
tion by on-site interviews and follow-up telephone calls to SEA officials.

Mailed Surveys. Kirst and Mosher have described the survey approach as involving numerical measurement of a restricted set of variables from a relatively large sample population. Mailed surveys of local school districts and local school personnel have been used in previous educational policy studies to determine the extent of implementation of educational policies at the local level.

For example, Killalea Associates (1978) assessed local compliance with federal desegregation and equal education laws. This study included mailed surveys to local school district personnel to determine the extent of implementation of educational policies. Advocating a similar approach, the Massachusetts State Department of Education (1982) has proposed a research design for evaluating the implementation of the state's basic skills improvement policy. This proposal includes surveys of school administrators, teachers, and local advisory committees to determine the extent of implementation of the state policy at the local school district level. Sorenson and Chapman (1985) have studied the implementation of the federal Family Educational Rights and Privacy Act. 
They surveyed secondary school counselors throughout the nation to determine the degree of compliance with the various provisions of this federal policy.

With its focus on determining the extent of policy implementation at local levels, the present study is similar to past research by Killalea Associates (1978) and Sorenson and Chapman (1985). However, the present study examines the implementation of state policy, while the prior studies examined federal policy. Combining Case study Interviews and Mailed Surveys. A number of authors have recommended the use or have actually used the case study and survey approach in combination. In a study of a special education policy on surrogate parenting, McLaughlin and London (1979) conducted mailed surveys of state officials on the extent of compliance with provisions of federal law. At the conclusion of their study, McLaughlin and London recommended the use of interviews with persons involved in the policy process. These interviews could be used to obtain information for an in-depth analysis of policy implementation by the states.

Smith and Tawney (1983) used both mailed surveys and interviews in a study of the implementation of an educational policy on parental involvement in special education compliance monitoring. Smith and Tawney first 
surveyed state officials to determine the extent of parental involvement. Next, they described the use of structured interviews to evaluate implementation of educational policy by SEA officials.

Summary. Some of the primary methods for research on the implementation and evaluation of educational policies are 1) surveys, 2) case studies using interviews, and 3$)$ techniques combining surveys and interviews. Using these methods, empirical information has been collected on the the nature of the policy process within governmental institutions.

\section{Empirical Findings on Character of the Policy Process} Problems with Policy Implementation. Ideally, implementation starts with the adoption of a policy and ends with the goals of the policy achieved. However, achievement of policy goals can be prevented by a number of factors. Quade (1982) has observed that the implementation of public policies can be modified by such forces as: implementing institution, pressure from competing agencies, court decisions, opposition of interest groups, and resistance from those whose behavior the policy was designed to change. Another impediment to policy implementation is the failure to design the policy in anticipation of the circumstances under which the policy 
will operate. The end result is the policy does not accomplish the purpose intended by policy-makers.

Bardach (1980) observes that problems with policy implementation may be attributed to a weak consensus of support for the policy, when the policy was adopted. In some cases, interest groups opposing the policy may be silent during the policy adoption stage because they are confident of success in preventing or resisting policy implementation.

Jones (1984) reports that most policy-making is based upon little information and poor communication. Jones believes that that many policies are developed and implemented without the problem being clearly defined. He asserts that policies usually reflect a consensus that was achieved, instead of a strongly held belief. At the implementation stage, policies requiring intergovernmental participation usually contribute to differences in interpretations of policy intent. These differences are usually not resolved. Jones has also observed that many policies are implemented without provisions for evaluating the effectiveness of the policy in bringing about desired consequences.

Quade (1982) recognizes that problems with policy implementation are particularly evident with novel, nonincremental policies. Particularly in complex bureau- 
cracies, it is important for the policy to be acceptable to all levels of the organizational hierarchy. Even with full authority and sufficient resources, changes in behavior can be difficult.

A review of problems of policy implementation indicates that impediments to implementation can include: a weak consensus at policy adoption, poorly defined policy intent or requirements, opposition by competing interests, and poor communication between governmental institutions. Lack of support for non-incremental changes within the implementing institution can also interfere with policy implementation. Next, the relations between state and local institutions responsible for implementing educational policies will be examined.

\section{Implementation Through Institutions: State Educa-} tion Agencies and the Regulation of Local School Districts. Since Kirst's (1970) call for the study of the political relationships and interactions between various levels and branches of government in education," researchers have attempted to grapple with issues involving relations between state and local units responsible for public education. Within the field of educational policy, Iannaccone (1972) has observed a growing gap between policy-making and implementation. He observes that many 
individuals within the educational bureaucracy believe that policy-making authority should reside with an intelligentsia outside the schools. He described this intelligentsia as being composed of I) educational theoreticians and researchers concerned with enhancement of learning or 2) activists concerned with social change. He observed that the failure to involve those responsible for policy implementation in policy planning resulted in a gap between policy formulation and implementation. Because of the failure to include school personnel in policy formulation, educational policies have ignored activities at the local building level. Consequently, policy initiatives from state and federal levels have resulted in few changes in local building operation. Iannaccone also observed that social change within the schools (i.e., integration) has been more successful, when the focus of change is the improvement of the quality of education, rather than using schools as an agent of social change. If change in school operation is desired, the explicit goal of change activities should be the improvement of educational quality.

After an analysis of local implementation of statemandated education regulations, Licopoli (1983) complained about the confusing and contradictory information transmitted from state officials to local school district 
personnel. To clarify relationships between the state and local levels, Licopoli recommended the study of the path of the policy process from the legislature to state and local administrators responsible for policy implementation. Consistent with Licopoli's recommendation, the purpose of this section is to review literature on the interactions between state and local levels from policy formulation to policy impact.

Dentler (1984) has viewed sharply rising costs, reduced revenues, and sharply divisive political issues as drawing legislators into education policy-making on almost all state and local practices. This increased legislative involvement has resulted in a rate of change that few SEAs have been able to control administratively. This rate of change has also resulted in difficulties for local school districts in incorporating legislative policy directives into daily operations.

Dentler (1984) notes that state legislation has frequently required changes in educational practices, but presumes that the SEA (i.e., Office of the State Superintendent of Public Instruction, OSPI) is capable of enforcing the changes without fiscal support. When fiscal support is not provided in legislation, the probability of implementation and compliance is dependent upon the quality of interactions between the SEA and 
local school districts (otherwise known as local education agencies, LEAs). The quality of interactions between state agency and LEAs may vary in terms of 1 ) degree of SEA involvement in the policies and practices of al1 LEAs in the state, 2) quantity and quality of SEA technical assistance to LEAs, and 3) SEA control over state resources for education. Dentler (1984) has found that most SEAs confine their activities to the state capital. While SEAs conduct outreach activities to LEAs, the staffs of SEAs tend to direct most of their activities to serving the SEA.

Dentler has concluded that SEA-LEA relations determine whether the implementation of educational improvements are confined to a few LEAs or are widespread. Because most SEAs are not organized to act as facilitators of policy changes, few SEAs are able to insure dissemination and institutionalization of policy changes in LEAs. Turnbul1 (1984) has identified impediments to implementation of policies at the local level. These impediments relate to 1) fiscal constraints on LEAs and 2) the need for the concurrence of a great number of individuals (i.e., teachers) with the policy. Turnbull contends that if state policy-makers overlook local costs associated with implementation of policy changes, they risk local opposition or half-hearted implementation of 
the policy. When local school personnel disagree with these state policy directives, "they weigh their own convenience and educational philosophies against possible consequences of noncompliance" (Turnbull, 1984, p. 221). To promote compliance, Turnbull asserts that state policy makers and administrators must provide 1) policy goals which are consistent with local preferences, 2) clear requirements, 3) funding, 4) sanctions for noncompliance, and 5) a policy that remains stable over time. The LEA can play an important role in facilitating changes in local practices in response to state policy initiatives (Turnbull, 1984). To increase the probability that a state policy will have an impact on local practice, Turnbull believes that the LEA should provide for local initiatives (i.e., board policies, administrative procedures) which persuade the implementors of the policy to change their behavior. Turnbull also contends that the LEA should provide resources to help school personnel understand and carry out the initiative (i.e., staff time for local in-service activities). The LEA should also integrate the policy initiative into other, "mainstream" school building activities.

A review of professional literature in education reveals an example of an educational policy analysis in the state of Washington. Doyle (1980) conducted an anal- 
ysis of the Washington state Student Learning Objectives (SLO) Law. After his analysis of the law, Doyle concluded that the Washington State Legislature 1) ignored the complexity of policy implementation, 2) provided no funding, 3) failed to allocate rewards for success, 4) did not provide for assistance or training in the development of implementation techniques, and 5) did not adequately provide for local involvement in objective setting. While some of Doyle's claims are subject to debate, his concerns point out some of the difficulties in implementing state legislated policies. A notable omission in Doyle's analysis was the role of the SEA in disseminating information and facilitating implementation of the SLO law. This role might include responsibility for establishing 1) minimum standards, 2) administrative rules, and 3) technical assistance to LEAs.

In summarizing, the implementation of state public policy initiatives appears to be dependent upon the provision of fiscal support or sanctions. Without these contingencies, the implementation of state policy may be dependent upon widespread involvement of the SEA in local school district activities, local fiscal support, and the integration of state policy changes into mainstream school activities. 
Governmental Institutions Responsible for Education in the state of Washington

In order to understand the implementation of a Washington state policy, the structure of institutions responsible for education in the state must be described. The Constitution of the State of Washington provides for the general structure of educational policy-making and administration at the state level. In Article IX Section 1, it is stated, "It is the paramount duty of the state to make ample provision for the education of all children residing within its borders...." Therefore, education within the state of Washington is the responsibility of the state. In Section 2 of Article IX, the constitution states, "The legislature shall provide for a general and uniform system of public schools..." This section appears to give the state legislature responsibility for the establishment of and general policy-making functions for public schools.

In Article III Section 22, the constitution states, "The State Superintendent of Public Instruction shall have supervision over all matters pertaining to the public schools, and shall perform such duties as may be prescribed by law..." This section provides the office of the Superintendent of Public Instruction (OSPI) with responsibility for the administration of public education 
in the state. The state legislature requires that the OSPI also perform the following functions:

...prepare and have printed such...rules and regulations for the governance of the common schools... and such other books and materials as may be necessary for the discharge of the duties of teachers and officials charged with the administration of laws relating to the common schools..." (Revised Code of Washington (RCWA) $28 \mathrm{~A} .03 .030(3))$.

This section provides OSPI with the responsibility for developing administrative rules and providing informational materials to assist local school personnel comply with laws governing public schools.

The State Board of Education (SBE) is referred to as "the voice of the public" in educational policy-making (Washington Office of the State Superintendent of Public Instruction, 1981). The SBE is composed of 17 lay persons, exercising authority in the following areas: 1) education and certification of teachers and school administrators, 2) curriculum requirements and courses of study, 3) management and the operation of public schools and vocational-technical schools. The SBE is particularly involved in the administration of the state school construction aid program. The state superintendent of Public Instruction acts as the executive arm of the SBE by carrying out and effectuating policies and regulations of the SBE. 
The state legislature has provided for intermediate and local levels of government in education below the state level. At an intermediate level are nine regional educational service districts (ESDs) which perform the following functions:

(1) Provide cooperative and informational services to local school districts; (2) Assist the superintendent of public instruction and the state board of education in the performance of their respective statutory and constitutional duties... (Washington office of the state Superintendent of Public Instruction, 1981).

According to this statement, ESDs are charged with assisting state agencies in the administration of state educational policies and providing informational services. The ESDs also administer cooperative programs for LEAs (i.e., data processing).

At the local level, the state legislature has delegated much authority to the local school district. Local school districts are governed by elected school board members who have broad powers and duties that are only limited by authority reserved to state bodies or delegated to state officials (Washington office of the State Superintendent of Public Instruction, 1981). The school district board of directors is responsible for enforcing the rules and regulations of OSPI and the SBE (RCW $28 \mathrm{~A}$. 58.101). The school district board of directors is empowered to make regulations not inconsistent with the 
rules and regulations of OSPI and the SBE (RCW $28 \mathrm{~A} .58$. 110).

In summarizing this section, the legislature is responsible for the provision of education in the state of Washington. By virtue of this responsibility, the legislature assumes primary policy-making powers in the state. State level bodies, including OSPI and the SBE, are responsible for the supervision of local school districts (LEAs). OSPI is responsible for carrying out and effectuating policies of the legislature and the SBE. Regional ESDs assist OSPI and the SBE supervise education in the state. At the local level, the LEA is delegated numerous functions involving policy-making and administration within local district boundaries.

\section{Summary}

Public policies are usually best explained in terms of multiple models of policy analysis. The goals of policy research can include scholarly contributions of theoretically relevant knowledge or the promotion of action on social issues. Surveys, case studies using interviews, or a combination of these methods represent primary techniques for collecting information on the nature of the policy process. Within the discipline of educational administration, the study of the policy pro- 
cess within and beçween insticutions appears particulariy relevant to the present study. A review of recent studies on the local implementation of state policy initiatives has revealed that the success of such initiatives is dependent upon the features of the legislation (i.e., accompanying fiscal sanctions), the ability of the SEA to have widespread impact on LEA functions, and local support of such policies. In the State of Washington, the state legislature is in a paramount position in educational policy-making. Supervisory and administrative functions are primarily delegated to the state education agency (OSPI). OSPI is assisted by regional ESDs in promoting state policy implementation by local school districts.

THE APPRAISAL OF SCHOOL ADMINISTRATORS

\section{Goals of Administrator Appraisal}

As the state policy of interest relates to the appraisal of school administrators, professional literature on this topic must be reviewed. This information will serve as a basis for the evaluation of policy impact. In a survey of elected officials of teacher and administrator professional organizations, over 908 of the respondents agreed that the following should serve as objectives of administrator appraisal: 1) professional 
growth of the administrator, 2) improvement of educational leadership, 3) identification of competencies for improvement, and 4) acknowledgment of quality performance. A majority also believed that appraisal should serve as a basis for determining employment status (e.g., promotion, reassignment)(Buser \& Banks, 1984). These objectives can be grouped into two general goals of administrator appraisal. The first goal is evaluation, which serves the purpose of making personnel decisions. The second goal is professional development, which serves to increase the effectiveness of the administrator. However, Skopec (1984) observes that these goals are rarely accomplished. Clearly, the effectiveness of the appraisal of administrative performance must be improved to accomplish these important goals.

\section{Current Status of Administrator Appraisal}

Legislation by state government is frequently required to insure that a valued activity is carried out by the public schools. The value placed upon a particular activity in the schools can sometimes be assessed by the willingness of legislators to pass laws requiring that the activity be carried out. Before 1971, only four states required that school administrators be evaluated. By 1983,22 states required that administrators be evalu- 
ated. This finding suggests that administrator evaluation has only recently been perceived as a valued activity. Nevertheless, administrator evaluation was not required in a majority of states, as recently as 1983 (Wuhs \& Manatt, 1983).

If administrator evaluation is carried out by a school district, the evaluation is typically carried out in a superficial manner by one person--the superintendent (Hunt \& Buser, 1977). The results from a survey of school principals in California illustrates problems affecting administrator evaluation. of those principals surveyed, about 508 were neither informed of the evaluative criteria, nor aware of the information used as a basis for their evaluation. Principals, who were aware of the evaluation criteria, often stated that the information collected was informal, non-systematic, and seldom based on direct observation. If they were aware of the information sources, the principals reported that hearsay and gossip were important sources of information (Deal et al., 1977).

The superficiality of the superintendent's evaluation of the principal may be related to the nature of the principal's job. Licata (1980) perceives the principal as being required to carry out job responsibilities with a high degree of autonomy. This autonomy is needed for 
someone who is frequently called upon to make decisions without the assistance of a superintendent or other superior. The superintendent's suggestions to the principal are perceived as being contradictory to the usual autonomy that is encouraged by the principal's daily activities. Licata perceives these dynamics as encouraging resistance toward professional development on the part of the principal. The superintendent may avoid giving feedback on professional performance, because the feedback may be perceived as an infringement on the principal's professional autonomy.

Licata (1980) observes that appraisal of administrators is rarely oriented to foster and guide the professional development of school administrators. Instead, appraisal data is more typically used for making personnel decisions relating to salary, tenure, promotions, demotion, or dismissal. Currently, professional development is often limited to suggestions for improvement by the supervisor and "one shot" in-service presentations. In both cases, no provisions are typically made for follow-up or support to foster application of newly acquired skills (Licata, 1980).

Bailey (1984) observes that administrators frequently find little time to engage in improvement activities. In addition, many administrators have insufficient 
knowledge to set up a self-improvement program. Bailey contends that administrators must realize that to increase their effectiveness, their self-improvement practices must be successful.

How can administrator appraisal practices be made more useful? Licata (1980) argues that information from subordinates should be a prime source for guiding the administrators' self-improvement. However, Solomon (1983) observes that principais tend to avoid feedback from their staff. Instead, principals rely on information from student test scores, comments by parents, and information from district specialists.

\section{Sources of Information for Administrator Appraisal}

In Buser and Banks' (1984) study, officials of teacher and administrator professional associations were asked, "Who should evaluate principals?" Ninety-five percent of the respondents believed that superintendents should appraise principals. Ninety-four percent of respondents believed that principals should engage in self-appraisals. Two-thirds of the respondents believed that teachers should appraise principals. The following percentages of the responding administrators supported teacher appraisal: 748 of the secondary principals, 648 of the superintendents, and 408 of the elementary school 
principals.

A majority of Georgia school administrators also expressed the opinion that appraisal information for principals should be collected from both superordinates and subordinates. However, they believed that the superintendent should be responsible for making the final judgment regarding the principal's performance (McDonald, Owens, \& Harrison, 1979).

Because the subject of teacher appraisal of principals is a "touchy one," Solomon (1983), an elementary school principal, could only get about 25 out of 77 administrators in her school district to complete a questionnaire on the topic. From the group of 25 who chose to participate, one-half elected to remain anonymous. In responding to survey questions, about 508 of the principals were skeptical or guarded about the idea of being appraised by their teachers. Four principals responded negatively to the suggestion that teachers evaluate them anonymously. However, eleven out of twenty-five principals saw the subordinate appraisal as a chance for the principal to make professional growth. As Sanacore (1976) reasons, "Since teachers have improved through administrative assessment, it seems probable that administrators can improve through teacher evaluation" (p. 98$)$ 
As early as 1960, Weldy observed that teacher appraisals of administrators can result in improved administrative performance. Weldy noted that teacher appraisals can improve administrator performance, if the teacher has a responsible and constructive attitude and the administrator is sincerely interested in improvement. Featherstone and Romano (1977) believe that school personnel affected by the decisions of an administrator may be in a better position to appraise the results of administrative performance, than the administrator's supervisor. Similarly, Solomon (1983) observes that the classroom teacher may be in the best position to suggest improvements in administrative skills. Bailey (1984) recommends the use of faculty feedback as a source of information to guide self-improvement activities of school administrators. Chamberlin (1980) believes that teacher feedback assists the principal in 1) building greater rapport with his/her staff and 2) providing information on faculty perceptions of school needs. Beaubier and Thayer (1973) recognize that it is advisable for a successful leader to check his/her intuitions about the effectiveness of the school organization. They advise against an informal, subjective method that might result in selective, biased perceptions. Instead, they advise that a more objective and formal assessment 
of subordinate attitudes might serve to 1 ) validate the leader's perceptions and 2) provide the leader with insights into potential and actual problem areas.

Support for Teacher Appraisal of School Administrators from Organizational Theory

Bridges (1982) believes that those assessing administrator impact should not only identify the criteria they use, but should also provide the theoretical and/or empirical significance of the indicators. The indicator of impact and the significance of the indicator depends on whether the researcher views the organization as a natural, political, rational, open, or career system. If one adopts a natural system or a political system perspective of the organization, then appraisal input from subordinates may be an important indicator of organizational effectiveness.

In the natural system, organizations are viewed as "collectives" that simultaneously achieve specified goals and engage in other activities necessary to preserve the group as a social unit (Scott, 1981). Bridges contends that relevant outcomes using this model include employee satisfaction and morale, as well as organizational survival. Teacher feedback could certainly serve as an indicator of employee satisfaction and morale. 
In the political system approach, the organization is composed of subgroups and constituencies which hold differing views regarding the nature and goals of the organization (Scott, 1981). In this model, administrators should be assessed in terms of how well they are able to satisfy the interests and goals of the various subgroups and constituencies. Teachers and other certificated staff represent a subgroup from which information could be obtained to assess the skill of the administrator in satisfying subgroup interests.

Related to the political system approach, Cross (1981) believes that universally accepted criteria of effectiveness are rarely available to principals. Cross argues that effectiveness is a construct that will represent someone's values and biases. Consequently, school administrators will always be placed in a position of negotiating effectiveness criteria with the professionals and patrons with whom they interact. Cross believes that principals should not only have their own methods for assessing their administrative effectiveness, but they should also take into account the expectations of others. In order for the schools to reach organizational goals, it is believed that teachers and administrators must have similar perceptions of organizational events. However, research indicates that teacher and administra- 
tor perceptions may differ on the fundamental task of instructional leadership. In a study of instructional supervision, a Tennessee state task force collected survey information from teachers, principals and instructional supervisors (Lovell \& Phelps, 1977). The survey data revealed that the principals and instructional supervisors viewed their instructional leadership activities as generally adequate, while the teachers viewed these activities as grossly inadequate. This divergence in the perceptions of administrative performance may result in organizational goals that fail to meet the immediate and fundamental needs of the organization. It is believed that administrators and teachers must have similar perceptions of basic organizational needs to facilitate efforts to achieve organizational goals. In order for administrators to know teachers' perceptions of organizational needs, administrators must give teachers the opportunities to express their beliefs. However, studies of teacher attitudes have revealed teachers believe that they do not have the opportunity to express opinions or concerns about school issues (Valentine, 1981). 
Support for the Appraisal of School Administrators by Subordinates from Leadership Theory

As noted in the foregoing discussion, if one adopts a natural system or a political system approach, then teacher input can serve as an important indicator of administrator effectiveness. From the perspective of leadership theory, teacher involvement in decision-making can be beneficial to the organization and its members. Appraisal by subordinates may represent an example of teacher involvement in decision-making, which is beneficial to the school organization.

Rainey (1983) notes that autocratic and authoritarian types of leadership are based upon the assumption that the necessary intelligence for leadership is confined to a few superior beings that are innately endowed with the right and ability to control others. From the perspective of the democratic leadership style, it is assumed that all members of the organization can potentially make valuable contributions to determining the direction of organizational activities.

Outside the school environment, research has shown that workers under democratic forms of leadership are more efficient than workers under autocratic leadership patterns. Defined as worker satisfaction and achievement of work goals, this efficiency under democratic leader- 
ship is particularly evident by the workers' ability to work and cope with problems when the leader is absent (Swan, 1980).

Supporting the applicability of the democratic leadership style in the schools, Gorton and McIntyre (1978) have found that outstanding principals tend to involve teachers in decisions and maintain open communication with them. Rainey (1983) has found such facets of democratic leadership as supportiveness, openness, informality, and trust are related to positive organizational outcomes. These positive outcomes include 1 ) more accurate communication, 2) increased initiative and spontaneity, which improve problem-solving skills of the subordinates, 3) greater production and improved work quality and 4) greater commitment to organizational goals. If a democratic leadership style contributes to a greater commitment to organizational goals, then this leadership style may also increase the teacher's selfcontrol and motivation to accomplish these goals (McGregor, 1960). By increasing the self-control and motivation of the worker, the school administrator may have less need to rely on the "carrot and stick" approach to motivate teachers. Rather than manipulating safety and security needs, the administrator may utilize needs of esteem and self-fulfillment to increase motivation. 
In using a more democratic leadership style, the supervisor may be provided with information from individual teachers on the most appropriate leadership style, when interacting with the teacher. Using the concepts from situational leadership theory (Hersey, Blanchard, \& Hambleton, 1980), teacher feedback to the supervisor may provide the supervisor with information regarding the appropriate levels of relationship and task-oriented behavior when interacting with the teacher. The supervisor may be able to determine whether telling, selling, participating, or delegating are more appropriate leadership styles in different interactions with teachers. By using more appropriate levels of relationship and taskoriented behavior, the supervisor may more effectively provide guidance and support to staff members. At the same time, the supervisor may better use the talents of staff members through the delegation of responsibility. It is believed that the solicitation of input from teachers serves as one component of a democratic leadership style. The solicitation of teacher input may also reap some of the benefits of the democratic leadership style.

Empirical Support for Teacher Appraisal of Administrators From a review of the literature on the effective- 
ness of the elementary principal, Cross (1981) has found that appraising principals on the basis of school standardized test scores is ill-advised. He believes that leadership effectiveness can be better based on indicators of. teacher morale, good school climate, and innovativeness of school programs. After a review of research on principal evaluation, teachers were found to be the best evaluators of principals (ERIC Clearinghouse for Educational Management, 1980). While other district personnel and outside observers may provide useful evaluative information, research has shown that principal self-evaluations are insufficiently objective. Ellett (1977) has described a survey of elementary and secondary school teachers on the performance of their building principals. Using the Principal Performance Description Survey, Teacher Edition, Ellett explored relationships between competencies of school principals and validating factors. These validating factors included characteristics of the school environment (i.e., school climate) and outcome variables (i.e., student school achievement). As evaluated by teachers, the principal's effectiveness was found to be positively related to teacher's attitudes toward the school. In turn, these attitudes toward the school were related to the educational effectiveness of the school, as measured 
by student average daily attendance. Ellett's study

illustrates that teacher ratings may provide useful and accurate information on the principal's influence on the educational effectiveness of the school.

Urbanski (1986) reported of a district-wide evaluation of administrators by teachers in Rochester, New York. This evaluation was initiated by the teachers to identify problems in school administration and foster administrator accountability. The 2,500 members of the Rochester Teacher Association rated district administrators on 21 factors related to job performance. The results of the evaluation indicated that administrators were most highly rated in the areas of 1 ) adhering to negotiated contracts and 2) treating faculty with dignity. However, administrators were generally given low ratings in 1) providing instructional leadership, 2) maintaining high staff morale, and 3 ) welcoming constructive criticism. Urbanski believed that the ability to accept constructive criticism was an important characteristic of an effective leader. He believed that accepting such criticism can make the administrator more effective and may increase staff morale.

Solomon (1983) has found that teacher feedback may better the principal's administrative skills and improve the work climate of the school. Solomon found that the 
principal's perceptions may differ greatly from perceptions of teachers. This discovery was made only after soliciting feedback from the instructional staff. Solomon reported a number of positive benefits by soliciting feedback from teachers on her performance as a principal. First, Solomon found that the feedback may force the principal to examine his/her administrative style. A principal may no longer assume how subordinates feel. Instead, the principal may be more inclined to ask for opinions and ideas. Second, teachers may feel that the principal is more approachable, as a result of the appraisal. The appraisal may show teachers that the principal is sensitive to the concerns of the instructional staff. Solomon reports that the appraisal may provide information on how supportive the principal is perceived by the teachers. Appraisal information may also give principals indications of how well they have involved their staff on changes in school practices. For Solomon, the appraisal illustrated that principals can sometimes make mistakes, and that they need not be perfect. Solomon believes that, like teachers, administrators "...need to feel uncomfortable, shaken, and forced to look at themselves so as to improve..." (p. 17). 
Disadvantages of Appraisal by Subordinates

From the prior review, it was found that appraisals of principals by teachers have yielded information on the effectiveness of the principal and have helped principals improve their administrative skills. However, a review of the research has also revealed problems with the appraisal of school administrators by subordinates.

Weldy (1960) noted that anonymous responses by teachers resulted in difficulties responding to complaints. He also found that teacher ratings were based upon isolated incidents, which were not always representative of the principal's performance. Some teachers could not rate principals fairly in all areas, because they were not aware of the principal's performance in all areas. While the evaluation gave the teachers the opportunity to express complaints that might not be exposed otherwise, some disgruntled teachers were given one more opportunity to "let off steam."

In Martin's (1979) experiment with "reverse evaluations" in a health sciences university library, a major problem encountered in soliciting information from subordinates involved the identification of the subordinate providing the information. If the subordinate failed to sign the appraisal, the appraisal was frequently difficult for the supervisor to evaluate, because the identity 
of the subordinate was unknown. If the subordinate was required to sign the appraisal, inadequate numbers of appraisals were returned and the appraisals tended to have higher ratings. From their involvement in this process, supervisors participating in the appraisals concluded that the subordinates could not remain objective while evaluating their supervisor. However, Martin asked, "Can supervisors really be any more objective while evaluating employees than employees can be while evaluating supervisors?" (p. 27 ).

Licata (1980) notes that some principals argue that the administrator's application of organizational sanctions against teachers may create hostility that might negatively bias teacher appraisals. Because of this, many administrators question the accuracy of these ratings. Consequently, Licata recommends that teacher ratings should be regarded as tentative. Licata believes that these ratings should be corroborated with direct observations.

Summary of Research on the Appraisal of School

\section{Administrators by Subordinates}

In summarizing, the appraisal of school administrators has two primary goals. These goals include (a) evaluation for making personnel decisions and (b) assess- 
ment to guide professional development activities. However, some believe that, in practice, the quality of administrator appraisal is inadequate to meet these goals. Appraisal for the professional development of administrators appears to be particularly inadequate. In exploring potential sources of appraisal information, it has been asserted that teachers can provide accurate and useful information to assess administrative performance. From a theoretical perspective, several different models of organizational behavior have identified teacher input as an important indicator of organizational effectiveness. Soliciting input from teachers on administrator effectiveness may also enable the organization to reap benefits of a democratic leadership style. The solicitation of teacher input may increase teacher involvement in decision-making. In turn, this involvement may benefit organizational functioning.

Educational research has lent support to the importance of teacher appraisals of principals. Teacher assessments have been found to accurately reflect the educational effectiveness of public schools. When undertaken, teacher appraisals may also provide useful information to guide the professional development activities of administrators.

Primary problems related to subordinate appraisals 
of school administrators involve 1) subordinates' Iimited opportunities to observe administrator performance, 2) procedural difficulties regarding the anonymity of appraisers, and 3) skepticism of certain school administrators about the accuracy of teacher ratings. Even with these difficulties, the appraisal of school administrators by teachers may represent a valuable source of information to guide administrators' professional development efforts.

\section{SUMMARY OF THE LITERATURE REVIEW AND STATEMENT OF THE RESEARCH QUESTIONS}

\section{Summary of the Literature Review}

As a public policy, the Washington state law providing for appraisal by subordinates can be studied using a variety of conceptual models. Certain elements of these models can be applied to the present research problem to guide inquiry. The policy process and the influences of institutions and interest groups appear to be particularly relevant to the study of the Washington state policy.

In the State of Washington, the state legislature is in a paramount position in educational policy formulation. Supervisory and administrative functions are delegated to the state education agency (OSPI), which has 
primary responsibility for promoting the implementation of state policies in local school districts. Therefore, study of the policy process would typically include the state legislature, OSPI, and local school districts. Interest groups assume an influential role in shaping public policy. Consequently, an examination of the role of interest groups in the implementation of the Washington state policy seems necessary.

Using the process model of policy analysis, the implementation and evaluation stages of the process model can be applied to the Washington state policy on the appraisal of school administrators. Using a path analysis advocated by Licopoli (1983), a number of activities could hypothetically occur at each stage of the educational policy process.

After the formulation and adoption of statute, rules and regulations could be developed by OSPI at the implementation stage of the policy process. These rules and regulations could provide more specific interpretations to facilitate implementation of the legislation. OSPI could also communicate to local school districts regarding the necessity to comply with statutes, rules, and regulations. Responding to these communications, local school boards could adopt policies to promote the implementation of the state law by local school adminis- 
trators. School administrators could then develop strategies and techniques in their buildings that complied with the requirements of the state policy. After these strategies were attempted, the effects of the strategies could be evaluated as to their effectiveness in meeting their desired ends. Using information from this evaluation, policies at state or local levels may be modified to increase their effectiveness. If the policy is judged to be ineffectual, the policy may be terminated.

Have governmental institutions in the state of Washington progressed through this hypothetical policy process with regard to the state policy on appraisal of school administrators by subordinates? As no past studies have explored this question, the present study will be directed toward this problem.

While no research could be found that studied the specific effects of the strategy described in the state policy, research has been cited that addressed the effects of the general strategy of appraisal by subordinates. A number of writers of professional literature in educational administration believe that this strategy can be an effective way to improve the performance of school administrators. The use of subordinates to appraise the performance of school administrators has received support 
from theoreticians, who believe it to be a useful riethod for involving subordinates in decision-making processes. By involving subordinates in decision-making, some writers predict better decisions will be made and greater commitment to organizational goals will result. Other theoreticians view appraisal information from subordinates as an important indicator of organizational effectiveness. Researchers studying this topic have found that improved administrator performance has resulted from having subordinates appraise their supervisor. However, some practicing school administrators have questioned the accuracy of appraisals of school administrators by subordinates, because of the organizational sanctions that the administrator may employ against subordinates. An evaluation of the state policy on appraisal of school administrators by subordinates provides an opportunity to assess the effectiveness of this type of appraisal for improving administrator performance.

\section{Statement of the Research Questions}

In analyzing the state policy on appraisal of school administrators by subordinates, research questions will be directed toward studying activities occurring at the implementation and evaluation stages of the policy process. Information is needed to describe activities 
occurring at the state level which contributed to the implementation of the state policy on appraisal by subordinates. A study of the state policy should include an assessment of the local school district response to the state policy. A study of the local school district response should include an examination of the extent of 1 ) local school district policy adoption consistent with state policy and 2) local school administrator implementation of the strategy of giving subordinates the opportunity to appraise. In order to determine whether the effects of policy implementation are due to the strategy of giving the opportunity to appraise or actual appraisal activities, it is also necessary to determine whether school personnel actually appraise supervisor performance, when given the opportunity. The impact of the strategy can then be determined by asking school personnel their opinions on the effects of implementing this strategy of appraisal. In order to determine the nature of the implementation activities and the impact of these activities, the following research questions have been asked:

\section{POLICY IMPLEMENTATION QUESTIONS:}

1. What actions were taken by educational personnel at the state level to insure that the state policy on appraisal of school administrators by subordinates was implemented by local school districts and school administrators? 
2. To what extent have local school districts adopted policies governing school administrator appraisal by certificated subordinates in conformance with state policy?

3. To what extent have school administrators given their subordinates the opportunity to appraise their administrative performance, as required by state law?

POLICY EVALUATION QUESTIONS:

4. When given the opportunity, as required by state law, to what extent do certificated subordinates actually appraise their supervisor's performance?

5. When the strategy described in state policy is implemented, what are the attitudes of professional school personnel toward the appraisal of school administrators by their certificated subordinates? 
CHAPTER III

METHODS

Like previously cited studies of the policy process (i.e., Smith \& Tawney, 1983), the method of this study included interviews and mailed surveys to attempt to answer the research questions on policy implementation and evaluation. The interview methodology served as a vehicle for assessing efforts to implement the state policy. The incerview methodology provided information for a case study of policy implementation at the state level. The survey methodology was used to determine the effects of state level activities on policies and practices at the local levels. The survey approach also assessed and evaluated local efforts to implement the strategy of appraisal of school administrators by subordinates. In support of combining the survey and case study approach, Boyan (1981) observes,

(P) lanned and systematically implemented juxtaposition of survey analysis and case studies in the same line of inquiry is far from common in educational administration and could advance significantly the production of reliable data (p. 10). 
METHODOLOGY FOR RESEARCH QUESTION ONE

ON STATE IMPLEMENTATION

The first research question is stated as follows: What actions were taken by education personnel at the state level to insure that the state policy on the appraisal of school administrators by subordinates was implemented by local school districts and school administrators? The purpose of the methodology addressing this research question was to determine and describe actions taken by personnel at the state level to implement the state policy. To provide a context for studying these actions, the methodology was also designed to collect information on the relations among officials in positions of influence on education policy-making in the state of Washington.

The interview methodology was used in the present study to obtain in-depth background information from a limited number of individuals about the complexities of the implementation of the state policy in the state education bureaucracy. The interview methodology is well-suited to the study of individuals located at one site (i.e., the state capital). It is believed that the format of the interview approach can elicit information 
on perceptions of complex phenomena comprising the policy process within and across organizations at the state level. The relevance of the interview methodology for the description of complex phenomena is supported by Kirst and Mosher's (1969) description of a "case approach." This approach usually addresses a large number of complex relationships by the collection of qualitative data derived from interviews. The interview format also provides the opportunity for clarification of questions and concerns arising from interviewee responses. The use of the interview methodology for collecting data relevant to the first research question was also based upon the prior use of this methodology in studies of the implementation of federal policy initiatives by state education agencies (i.e., Beuke, 1980; Blaschke, 1980).

\section{Subjects}

The subjects were six officials in government and associations at the state level. These officials included individuals in the office of the superintendent of Public Instruction (OSPI), associations of education professionals, and the Senate Education Committee. Officials in OSPI included the Director of Professional Education and the Agency Rules Analyst. In the associations of education professional associations, officials 
included representatives of the Washington Education Association (WEA), Washington Association of School Administrators (WASA), and Washington State School Directors' Association (WSSDA). These officials were chosen on the basis of their experience in association relations with education policy-making bodies. Finally, the staff coordinator for the Senate Education Committee was interviewed to obtain information from the perspective of the legislature. Having experience on both the House and Senate Education Committees, this individual provided a comprehensive view of education policy-making in the legislature. All prospective interviewees had given their approval for the interview, prior to the interview date.

Instruments

The interview format used in the interviews of the state officials is presented in Appendix A. This interview format was constructed by the investigator to obtain information about 1) relations among state governmental units, 2) the state education policy, process generally, and 3) the implementation of the state policy on the appraisal of administrators by subordinates. The interview questions were examined by an official at the OSPI, who was not formally interviewed. The questions were 
examined to determine the appropriateness of the questions to obtain desired information. Some questions were modified based upon this consultation.

\section{$\underline{\text { Procedure }}$}

In June of 1986, the state officials were interviewed by the investigator. Each interview was conducted at the official's office. The interviews were structured by specific open-ended questions presented in Appendix A. Intervening between each of these questions were probes to have the official clarify or elaborate on their answer. With the official's prior approval, each interview was audiotaped to ensure the reliability of information obtained from the written protocol.

METHODOLOGY FOR RESEARCH QUESTIONS TWO THROUGH FIVE ON LOCAL POLICY ADOPTION, IMPLEMENTATION, AND EVALUATION

A survey methodology was used to study the second through fifth research questions. The survey approach was used to collect information from a large number of individuals at the local level. The survey approach appears to be one of the most feasible approaches for collecting information of a limited scope from a large number of individuals at different locales. Kirst and 
Mosher (1969) support this contention by describing the survey approach as being a methodology, in which

...(a) restricted set of variables, generally susceptible to numerical measurement, are isolated and accepted as indicators of more general concepts. The variables are then studied in a relatively large and representative sample population (p. 633).

In the present study, the use of the survey approach appeared to appropriate for inquiry on research questions two through five, because these questions addressed a limited number of practices by school personnel across the state. Research findings from large and representative samples were believed to enable more valid generalizations about state-wide practices, than might be possible with a case study approach. More specifically, the survey approach provided information on the extent of the implementation of the appraisal strategy described in state policy. Using this approach, data was also gathered on whether the strategy was effective in improving administrator performance. In addressing these topics, the survey approach indirectly provided information on the effectiveness of state level officials in promoting implementation of the state policy on appraisal by subordinates. In a manner similar to the present study, surveys mailed to local school districts and local school personnel have been used in prior education policy stud- 
ies to determine the extent of implementation of education policies at the local level (i.e., McLaughlin \& London, 1979; Smith and Tawney, 1983).

Methodology for Research Question Two on Local Policy Adoption

The purpose of the following methodology was to gather information on the second research question. This research question addressed the extent to which local school districts have adopted policies in response to state legislation on the appraisal of school administrators by certificated subordinates.

Subjects. The subjects for the study of local policy adoption were respondents to a survey of 100 school districts in the State of Washington. The school districts were chosen at random from a directory of school districts in the State of Washington (Superintendent of Public Instruction, 1985). Each district in the directory was assigned a number and selected on the basis of a table of random numbers provided by Myers (1972).

Instruments. The survey and accompanying cover letter sent to the school districts are presented in Appendix B. The survey was developed by the investigator to determine directly the extent to which local school boards have adopted policies that are consistent with 
state policy on appraisal by subordinates. The survey was printed on a self-addressed, stamped postcard.

Procedure. In June of 1986 , the survey was sent to the Assistant Superintendent for Personnel for each of the school districts selected. If no Assistant Superintendent for Personnel was 1 isted for the district in the directory of administrative staff, the survey was sent to the Superintendent of Schools in each of the school districts selected.

Methodology for Research Questions Three Through Five on Strategy Implementation and Evaluation

In addressing research question three, this section will describe the method used to assess the extent to which subordinates are provided with the opportunity to appraise administrative performance, consistent with state policy. This method was used to collect information on research question four, which is concerned with the extent of actual appraisal activities, when subordinates are given the opportunity in the manner described in state policy. This method was also used to collect information on research question five. Research question five sought data on the attitudes of school administrators, teachers, and support persons toward the strategy of appraisal described in state policy. 
Subjects. The subjects were the respondents to a survey distributed to 200 school administrators in the state of Washington. The following numbers of administrators were selected: 40 superintendents of schools and 160 middle level administrators. The middle level administrators included elementary and secondary school principals and special education administrators. The superintendents were chosen from the Washington Education Directory, a directory of all school administrators in the state (Superintendent of Public Instruction, 1985). The superintendents were chosen randomly by 1) assigning all superintendents a number and 2) selecting each based upon a list of random numbers provided in Myers (1972). This procedure was repeated for the selection of the group of middle level administrators.

The subjects were also the respondents to a survey distributed to 160 public school teachers and certificated support personnel in the state of Washington. The certificated support personnel included the following groups: school counselors, school psychologists, speech therapists, occupational therapists, and school nurses. Because lists of the names of teachers and support staff were unavailable for personnel state-wide, the sampling of teacher and support staff was limited to a region in southwest Washington. A large percentage $(80 \%)$ of the 
teachers and support staff from this region were available to be randomly sampled for the survey. Teacher and support personnel were selected by assigning all individuals a number and selecting each person based upon a 1 ist of random numbers provided in Myers (1972).

Instruments. An example of the survey and cover letter sent to school personnel is presented in Appendix C. The survey presented in Appendix $C$ was specifically designed for middle level administrators. Similar surveys were developed for teachers and superintendents. The surveys were developed to assess directly whether subordinates are given the opportunity to appraise their supervisor's performance. When subordinates are given the opportunity to appraise their supervisor's performance, the surveys are designed to assess whether subordinates actually appraise their supervisor's performance. In cases where subordinates were given the opportunity to appraise, the survey was designed to assess directly the attitudes of subordinates toward this strategy of appraisal of school administrators by subordinates.

Item $3 a$ of this survey was asked of all administrators to determine the extent of implementation of the strategy of appraisal by subordinates described in state policy. To assist in the attribution of impact of the strategy, question $3 b$ was asked of all administrators, 
while question 7 was posed to middle level administrators, teachers, and support staff. To determine the actual impact of the strategy, questions $3 c$ and $3 d$ were asked of all personnel reporting involvement in strategy implementation. Question 6 was posed to middle level administrators, teachers, and support personnel to validate strategy implementation rates reported by the supervisors of these groups.

Procedure. Prior to collecting data for addressing research questions, a pilot study was conducted by distributing surveys to 10 teachers and middle level school administrators. The school personnel were asked to comment on whether the survey questions were clearly stated. The personnel were also asked to respond to survey questions. Their responses were evaluated to determine whether their answers were relevant to the questions asked. Changes in the surveys were made from the information gathered in the pilot study.

To collect information to answer research questions three through five, the surveys and cover letters were distributed to school personnel by mail in May and June of 1986. Self-addressed, stamped envelopes were also included in the mailings. 
SUMMARY OF METHOD

The interview and survey approaches to data collection were used together to collect information on the state policy on appraisal of school administrators by certificated subordinates. The interview methodology was used to collect in-depth qualitative information on the efforts of officials at the state level to promote local implementation of the legislative policy (research question 1).

The survey approach, on the other hand, was used to collect information on the extent of local policy adoption consistent with the state law on appraisal by subordinates (research question 2). The survey approach was also used to assess appraisal strategy implementation and impact (research questions three through five). Information on local implementation and impact, in turn, provided information on the effectiveness of state officials in promoting local compliance with the state education policy. 
CHAPTER IV

RESULTS

In this chapter, data collected from the use of the research methods will be summarized. Research findings will be described within the context of implementation and evaluation stages of the policy process.

INTERVIEWS OF STATE LEVEL OFFICIALS PROVIDING QUALITATIVE DATA ON STATE LEVEL IMPLEMENTATION

\section{Policy Implementation}

The interviews of state officials provided information to answer the first research question. The first research question asked: What actions were taken by education personnel at the state level to insure that the state policy on appraisal by subordinates was implemented by local school districts and school administrators? To answer this question, interviews provided information on the officials' knowledge of activities designed to implement the state policy on the appraisal of school administrators by subordinates. They were also asked their opinions on responsibility for implementing this state 
policy. As a context for studying these topics, the officials were asked to describe the primary functions of their office and discuss their relationships with other agencies and organizations in educational policy-making. State Legislature. Duane Slate of the Senate Education Committee reported that his office was primarily responsible for researching current issues in education and assisting legislators in the development of educational policies. The legislative committee has periodic communications with OSPI, both to obtain OSPI input in formulating educational policies and to assess OSPI activities relating to the development of administrative rules. However, slate reported that his office was not responsible for on-going verification of policy implementation. Slate could not cite any specific actions by state level officials to implement the state policy on appraisal by subordinates. Instead, he said that he would not be surprised if WEA informed their local contract negotiators of the policy.

State Education Agency. In the state education agency (OSPI), Jim McMinn (Agency Rules Analyst) and Ted Andrews (Director of Professional Education) were interviewed. McMinn stated that his role primarily involved responding to the questions of school patrons and employees about the content of legislative statutes and admin- 
istrative rules. McMinn did not report any specific activities contributing to the implementation of the state policy on appraisal by subordinates. Instead, he reported that labor interests usually keep teachers well-informed on such issues.

Andrews' Professional Education office is responsible for monitoring implementation of the School Personnel Evaluation Statute, of which the state policy on appraisal by subordinates is a part. Andrews stated that he was unaware of any activities designed to implement the state policy. Instead, his office would provide information on the state policy, if it was requested.

His responses to interview questions indicated that his office had insufficient manpower to ensure the comprehensive implementation of the School Personnel Evaluation Statute by local school districts, Instead, his office solicited reports from school districts, which requested information on whether the school district complied with a limited number of basic provisions of the School Personnel Evaluation Statute. However, these reports did not request information from school districts regarding the state policy on appraisal by subordinates. He noted that not all school districts in the state provided this report on the most basic elements of the School Personnel Evaluation Statute. With the limited 
size of his staff, Andrews indicated that on-site verification of compliance with the School Personnel Evaluation Statute was impossible.

When Andrews was asked what sanctions should be applied for failure to comply with the provision for appraisal by subordinates, none were cited. Instead, Andrews noted that it was OSPI policy to respect and encourage local control.

Interest Groups. Officials in associations representing interest groups in education provided perspectives on roles of these associations in implementing educational policies. Dick Usitalo of the Washington State School Directors' Association (WSSDA) stated that one of the primary functions of his office was the development of model policies, which local school districts can integrate into their district policies and procedures. Regarding the state policy on the appraisal of school administrators by subordinates, Usitalo believed that a ruling by the Attorney General's office might be necessary to clarify the requirements of the policy.

Usitalo stated that he was unfamiliar with the state policy prior to the interview and was unaware of any attempts to implement this policy. He observed that appraisal by subordinates was probably being carried out in some school districts. However, he believed that 
appraisal was not being carried out in response or knowingly in accordance with the legislative policy on appraisal by subordinates. He questioned why WEA did not advocate local district compliance with this state policy. He stated that WSSDA would be more likely, than OSPI, to communicate information to local districts on the content of the state policy. He also believed that WSSDA could provide information to local school districts on whether they were in compliance with the requirements of the state policy.

John Fotheringham from the Washington Association of School Administrators (WASA) also had not known of the state policy previously and could not recall any activities at the state level to implement this policy. He believed that if an individual administrator requested information on the state policy on appraisal by subordinates, his office would strive to answer questions posed by the administrator. He believed that WEA would probably be most interested in whether the state policy on appraisal by subordinates was implemented or not. This judgment was apparently based upon the belief that strategy of appraisal by subordinates would increase teacher input into the management of the school. Michelle Radosevich, Assistant Executive Director for Governmental Relations at WEA, reported that she was 
not aware of any activities by state level officials to implement the state policy. She believed that OSPI was primarily responsible for insuring local school district implementation of the policy. To her knowledge, WEA had not had any involvement in the implementation of the state policy on the appraisal by subordinates. If WEA ever did become involved in the implementation, WEA's primary role might be processing teacher grievances arising from activities related to the implementation of the strategy of appraisal by subordinates. She expressed the opinion that the strategy of individual confidential conferences might not be desirable from the perspective of teachers, because of the potentially negative consequences to the subordinate for providing the appraisal. Instead, she believed that the appraisal of administrators by committees of subordinates might be a more acceptable way to evaluate the performance of administrators. Summary. The first research question sought to determine what actions had been taken at the state level to implement the state policy on appraisal by subordinates. The interviews of state level officials did not reveal any activities that might contribute to local implementation of the state policy on appraisal by subordinates. Instead, the interviews generated speculation from some that WEA might promote the implementation of 
the state policy. However, a high ranking official of WEA was neither aware of the state policy nor in support of the policy.

\section{Factors Contributing to Policy Implementation}

Having daily involvement in state educational policy-making, officials at the state level appear to be in a good position to ascertain factors contributing to the implementation of state policies. During the interviews, these officials provided their opinions on these factors. Slate of the Senate Education Committee believed that the implementation of a legislative policy was dependent upon the following factors: 1) a clear purpose to the policy, 2) the support of the individuals implementing the policy, 3) the salience of negative sanctions for failure to comply with policy, and 4) interest group complaints regarding the failure to comply with a policy. McMinn, the Agency Rules Analyst at OSPI, believed that the implementation of legislative statutes was frequently dependent upon the concerted effort of educational interest groups. He believed that an educational policy needed advocacy groups, whether the policy was a good one or not. Andrews of Professional Education at OSPI believed that popular interest in a policy has often contributed to the implementation of the state policy. 
From the perspective of interest group representatives, Usitalo of the State School Directors' Association believed that litigation frequently contributed to the implementation of legislative statutes. Fotheringham of the Washington Association of School Administrators believed that the implementation of legislative statutes is dependent upon effective communication following the adoption of the statute. He contended that agencies (i.e., LEAs) responsible for implementing the policy must be informed of how to implement the policy by the specific details of the law itself, implementing administrative rules, requirements from the state Board of Education and OSPI, Attorney General opinions, and local school district attorney rulings. Radosevich of WEA believed that the policy implementation was facilitated by the attachment of revenues to the implementation of the policy. The attachment of revenues might be carried out by making funding of programs contingent upon compliance with a policy. Radosevich also believed that controversy and complaints about policies increased the amount of interchange among education groups and OSPI, influencing the implementation and evaluation of legislative statutes.

In summarizing, the legislative committee staff coordinator and officials from the state education agency 
recognized the importance or interests groups in promoting the implementation of state policies. The legislative committee staff coordinator and interest group representatives perceived clear policy definition, funding, controversy, and litigation as contributing to state policy implementation.

\section{QUANTITATIVE DATA FROM THE SURVEY OF SCHOOL DISTRICT POLICIES}

While the first research question addressed implementation of the state policy at the state level, the second research question was directed toward assessing implementation at the local level. The second research question was as follows: To what extent have local school districts adopted policies governing school administrator appraisal by certificated subordinates in accordance with state policy?

of the 100 districts surveyed, 748 responded to the survey $(\underline{n}=74)$. Of the those districts responding, 78 of the districts $(\underline{n}=5)$ indicated that they had school district policies providing for the appraisal of school administrators by certificated subordinates. The remaining 938 of the respondents $(\underline{n}=69)$ indicated that they had no such policy.

After responding to the research question, respon- 
dents were invited to make general comments. Of those reporting that they did not have a district policy on the subject, five stated that appraisal by subordinates is optional or at the discretion of the administrator. Two respondents stated that the requirement for the strategy of appraisal by subordinates was included in the collective bargaining agreement.

In summary, the second research question addressed whether local school district policies had been developed in accordance with state law. The results of the survey of local school district policies indicate that few school districts have adopted local school district policies to reinforce the requirements of state policy on appraisal by subordinates.

QUANTITATIVE AND QUALITATIVE INFORMATION COLLECTED FROM SURVEYS OF LOCAL SCHOOL DISTRICT PERSONNEL

The mailed surveys of local school district personnel were designed to collect information on research questions relating to the extent and effects of appraisal strategy implementation by local school district personnel, which was consistent with state law.

Rates of Response to Mailed Surveys To determine the representativeness of the samples 
of school personnel, an examination of response rates to the mailed surveys was necessary. A summary of the number and percentage of school personnel responding to the Superintendent, Middle Level Administrator, and Teacher Surveys are included in Table $I$.

TABLE I

RESPONSE RATES OF SCHOOL DISTRICT PERSONNEL

\begin{tabular}{llc}
\hline Survey Group & $\frac{\text { Survey Total }}{n}$ & $\frac{\text { Response Rate }}{n}$ \\
\hline 1. Superintendent & 42 & $23(558)$ \\
2. Middle Level Administrator & 159 & $63(408)$ \\
3. Teacher and Support Staff & 154 & $97(638)$ \\
\hline
\end{tabular}

An examination of the response rates indicate a range of 408 for middle level administrators to about 608 for teachers and support staff. The number of surveys initially mailed differ from the survey totals in Table I. These differences are attributable to the fact that some surveys were returned uncompleted, because of the unavailability or an incorrect address for the individual. These surveys were not included in the totals in Table I. In addition, some surveys of one group (i.e., middle level administrator) were sent to members of another group (i.e., superintendent). These surveys were 
included in the latter group's total in Table I.

Quantitative Information on Opportunity to Appraise

The third research question was stated in the following manner: To what extent have school administrators given their subordinates the opportunity to appraise their administrative performance? To answer this question, school administrators and teachers were asked by mailed surveys whether they or their supervisor had been involved in the strategy of appraisal by subordinates, pursuant to state law. The percentages of respondents reporting that they had been given the opportunity to appraise consistent with the state policy are contained in Table II. These percentages are divided on the basis of whether they are reporting about their own behavior or their supervisor's behavior. Table II shows that the percentage of respondents indicating opportunity to appraise consistent with state policy range from 188 for the teachers and support staff to 298 for the middle level administrators.

To verify levels of opportunity to appraise, rates reported by superintendents were compared to the rates reported by administrators and teachers directly supervised by superintendents. As noted in Table II, 228 of the superintendents reported that they gave the opportun- 
ity to appraise. When those directly supervised by superintendents were asked whether their supervis - gave them the opportunity to appraise, 258 percent responded affirmatively.

TABLE II

RATES OF OPPORTUNITY TO APPRAISE

A. Supervisor Self-Reported Rates of Opportunity to Appraise ("What I do.")

Survey Type Implementation Rate n 8

1. Superintendent 5 228

2. Middle Level Administrator 17 298

B. Subordinate Reported Rates of Opportunity to Appraise ("What my supervisor does.")

\section{Survey Type}

1. Middle Level Administrator

2. Teacher and Support Staff $\frac{\text { Implementation Rate }}{\frac{8}{8}}$

A similar comparison was made for middle level administrators. The level of opportunity to appraise reported by middle level administrators was compared with the implementation rates reported by those supervised by middle level administrators. While the percentage of 
middle level administrators implementing the strategy was 298, those personnel supervised by middle level administrators reported a 208 implementation rate.

Thus, the results addressing the third research question indicate that about one-quarter of school administrators responding to the survey give their subordinates the opportunity to appraise their performance. Differences between supervisor and subordinate groups on the opportunity to appraise dimension range from 38 to 98 .

\section{A Comparison of Opportunity to Appraise with Actual} Appraisal

The fourth research question was as follows: When given the opportunity, to what extent do certificated subordinates actually appraise their supervisor's performance? This question was asked to determine whether the effects of appraisal were 1) exclusively due to the opportunity to appraise or 2) due to the opportunity and actual appraisal activities, together.

of those administrators giving their subordinates the opportunity, all 22 reported that at least some of their subordinates actually appraised their performance. For those administrators given the opportunity to appraise by their supervisor, 17 of 18 (948) reported that 
they actually appraised their supervisor's performance. The one administrator reporting that he did not appraise his supervisor's performance, reported that at least some of his subordinates appraised his performance, pursuant to state policy. Of those teachers and support staff reporting that their supervisor gave them the opportunity to appraise, 10 of 18 (558) reported that they actually appraised their supervisor's performance.

Because all administrators reported involvement in the actual appraisal activities, the effects of appraisal activities for administrators can be attributed to appraisal activities, as well as the opportunity to appraise. For teachers and support staff choosing not to appraise, effects may be only due to the opportunity to appraise. For those teachers and support staff choosing to appraise, the effects may also be due to appraisal activities. Consequently, analyses of strategy evaluation data for teachers and support staff will be divided on the basis of whether the individual actually appraised administrative performance, when given the opportunity.

Qualitative Data on Reasons for Appraisal by Subordinates

By requesting reasons for employing an appraisal strategy which was consistent with state policy, an attempt was made to determine whether legislative adoption 
of the state policy contributed to the use of the appraisal strategy. A summary of the most frequently cited categories of reasons for appraisal practices and the number $(\underline{N})$ of administrators citing each reason are presented in Table III. Five superintendents and seventeen middle level administrators provided this information.

A review of the reasons for appraisal activities indicated that none of the administrators reported carrying out appraisal activities to comply with state policy. Instead, reasons related to the evaluation and improvement of the administrator's performance and/or the school program.

Qualitative Information for the Evaluation of Strategy Impact

The fifth research question was as follows: What are the attitudes of school personnel toward the appraisal of school administrators by certificated subordinates, when the strategy described in state policy is implemented? This question prompted an evaluation of the impact of appraisal by subordinates. This type of appraisal was evaluated by those school personnel who had reported that either they or their supervisor had given the opportunity appraise supervisor performance in the manner described in state law. These school personnel provided an eval- 
uation of the state policy by reporting benefits and problems with such appraisal activities.

TABLE III

REASONS FOR APPRAISAL PRACTICES

CONSISTENT WITH STATE POLICY

\begin{tabular}{lc}
\hline \multicolumn{1}{c}{ SUPERINTENDENT GROUP } & N \\
Categories of Reasons Cited & 4 \\
\hline $\begin{array}{l}\text { Subordinates have the best knowledge of } \\
\text { what is working well and what is not. } \\
\text { Self-assessment and goal-setting. }\end{array}$ & 3 \\
\hline & MIDDLE LEVEL ADMINISTRAToR GRoup \\
\hline $\begin{array}{l}\text { Categories of Reason Cited } \\
\text { Assessment or improvement of administrator } \\
\text { performance. }\end{array}$ & 8 \\
Assessment or improvement of school program. & 6 \\
Get a better sense of staff perceptions. & 4 \\
\hline
\end{tabular}

Superintendents' Evaluation. As cited by the five superintendents giving their subordinates the opportunity to appraise, categories of benefits and problems with appraisal by subordinates are presented in Table IV. The number ( $N$ ) of superintendents citing each category is also presented. 
TABLE IV

SUPERINTENDENT REPORTED BENEFITS AND PROBLEMS WITH THE STRATEGY OF APPRAISAL BY SUBORDINATES

\begin{tabular}{lc}
\hline Benefits of strategy Implementation & $N$ \\
\hline $\begin{array}{l}\text { Assessment of personal and/or professional } \\
\text { growth (i.e., develop plan of self-improvement). }\end{array}$ & 5 \\
Improvement of superintendent's performance. & 3 \\
Evaluation of the school program. & 2 \\
\hline & N \\
\hline \begin{tabular}{l} 
Problems of strategy Implementation \\
\hline
\end{tabular} & 1 \\
Subordinate uneasy or hesitant, because \\
his/her success.
\end{tabular}

A review of the data presented in Table IV shows that all superintendents implementing the strategy viewed the strategy requirements as having some benefit. The positive themes cited in the superintendents' responses indicate that appraisal by subordinates can serve to assess and improve administrator performance. Appraisal by subordinates can also assess school effectiveness. Only one superintendent suspected that one or more subordinates feared reprisals, after making the appraisal of supervisor performance. 
Middle Level Administrators' Evaluation. Twentynine middle level administrators were in a position to evaluate the effects of the appraisal strategy. This group's most frequently reported categories of benefits and problems with appraisal are presented in Table $V$. The number ( $N$ ) of administrators citing each theme is also included in Table $\mathrm{V}$.

The responses of the middle level administrators parallel those cited by the superintendents. Middle level administrators perceived the assessment of administrative performance to be a primary benefit of appraisal of school administrators by subordinates. Administrators also felt that this type of appraisal was important for obtaining perceptions of events from the perspective of their subordinates. An improved school program, better administrator performance, and more desirable working relations between administrators and subordinates were other important results of the appraisal process. Primary problems with appraisal included the perception that subordinates felt fear and discomfort about appraising administrator performance. Subordinates apparently exhibit fear in anticipation of reprisals for making negative appraisals. Problems with getting teachers to respond in an open manner were also noted by the middle level administrators. 
TABLE V

MIDDLE LEVEL ADMINISTRATOR REPORTED BENEFITS

AND PROBLEMS WITH THE STRATEGY OF

APPRAISAL BY SUBORDINATES

\begin{tabular}{lc} 
Benefits of strategy Implementation & $\mathrm{N}$ \\
\hline Assessment of administrator performance. & 16 \\
$\begin{array}{l}\text { School improvement (i.e., better learning and } \\
\text { teaching environment, improved teaching } \\
\text { performance). }\end{array}$ & 11 \\
$\begin{array}{l}\text { Increased mutual respect, trust, collegiality, } \\
\text { or confidence between supervisor and subordinate. }\end{array}$ & 8 \\
Obtain teacher perceptions and concerns. & 8 \\
$\begin{array}{l}\text { Improved problem-solving and decision-making } \\
\text { capability, using teacher opinions and expertise. } \\
\text { Teachers feel ownership or more a part of the } \\
\text { school. }\end{array}$ & 7 \\
$\begin{array}{l}\text { Improvement of administrator performance. } \\
\text { Better or more honest, open communication. }\end{array}$ & 5 \\
\hline
\end{tabular}


Evaluation by Teachers and Support Staff. For teachers and support staff reporting that their supervisor had implemented the appraisal strategy, benefits of strategy implementation were divided into two groups. These groups included 1 ) ten subordinates who actually appraised their supervisor's performance and 2) eight subordinates who were given the opportunity, but chose not to appraise their supervisor's performance. The same division was made for the problems of strategy implementation. The most frequently reported categories of benefits and problems with strategy implementation and the number (N) of school personnel citing each are presented in Table VI.

A review of the teachers and support staff responses to strategy implementation indicates that some respondents appraising administrator performance have observed improvements in administrator performance or the school program, as a result of the appraisal. The primary benefit noted by the group choosing not to appraise was the appreciation of being given the opportunity.

Some teachers and support staff recognized the primary problem of appraisal as being an absence of changes in administrator behavior following the appraisa1. Discomfort about appraising administrator performance was a problem reported by both groups. 
TABLE VI

TEACHER AND SUPPORT STAFF REPORTED BENEFITS

AND PROBLEMS WITH THE STRATEGY OF

APPRAISAL BY SUBORDINATES

\section{BENEFITS}

1. Teachers and support staff, who have actually appraised their supervisor's performance.

Benefits of Strategy Implementation N

Able to change things for the better (i.e.,

improved school program, increased efficiency,

improved communication).

Provides the opportunity to praise them for the things that they are doing right.

2. Teachers and support staff given the opportunity to appraise, but choosing not to appraise.

Benefits of Strategy Implementation $\underline{N}$

Appreciate the chance. 4

Possibly increases administrator awareness of 2 certain issues related to administrator job performance. 
TABLE VI (Continued)

PROBLEMS
$\begin{aligned} & \text { 1. Teachers and support staff, who have actually } \\ & \text { appraised their supervisor's performance. }\end{aligned}$
Problems of strategy Implementation

Suggested Methods of Appraisal. While not specifically requested, a number of respondents provided their opinions on how school administrators should be evaluated by their subordinates. This information served as a source of evaluative data on how the state policy can be improved.

In reviewing methods of appraisal suggested by respondents, several administrators suggested that appraisal information should not be presented in an adversarial 
manner. Instead, the primary objective of the appraisal should be the personal growth of the administrator. A number of middle level administrators contended that open-ended questions should be included in the appraisal. Administrators disagreed on whether an annual formal evaluation of all administrators should be required.

Several teachers involved in strategy implementation also provided suggestions on how to improve appraisal by subordinates. One teacher maintained that staff members must be specific and objective, when appraising administrator performance. Another teacher indicated a preference for a written form, rather than a confidential conference.

Summary. Some administrators and teachers recognize that appraisal by subordinates can effectively assess and improve administrator performance. Appraisal by subordinates and also be useful for the evaluation and betterment of the school program. Better relations have been observed between supervisor and subordinates, as a result of such appraisal activities. The most frequently cited problems with appraisal activities related to 1 ) unresponsiveness of some administrators to suggestions made during the appraisal and 2 ) the reluctance of subordinates to appraise for fear of possible reprisals. 


\section{SUMMARY OF RESULTS}

The results of the present study showed that none of the officials interviewed reported any activities at the state level to implement the policy on the appraisal of school administrators by certificated sutordinates. The survey of local school districts revealed only a small percentage of districts have adopted policies on appraisal by subordinates that include the requirements of the state policy. Moreover, few school administrators were found to have complied with the requirements of the state policy by giving their subordinates the opportunity to appraise their performance. When given the opportunity, almost all of the administrators appraised their supervisor's performance. About one-half of the teachers and support staff appraised supervisor performance, when given the opportunity. School personnel in a position to evaluate the effects of appraisal strategy implementation reported the strategy serves to assess and/or improve administrator performance. Some school personnel reported improvements in the school program, when the appraisal strategy was implemented. However, according to some teachers and support staff, implementation of the strategy described in state policy neither ensures changes in administrative behavior, nor protects the subordinates against reprisals for making the appraisal. 
CHAPTER V

DISCUSSION

The purpose of this chapter is to provide an analysis of the implementation and impact of the state policy on appraisal of school administrators by certificated subordinates. This analysis will be carried out by evaluating data obtained from research methods. The data will be analyzed using professional literature on the topics of policy analysis and appraisal by subordinates.

POLICY IMPLEMENTATION AT THE STATE LEVEL

\section{Analysis of State Level Implementation}

The first research question addressed actions taken by education personnel at the state level to insure the strategy described in state policy was implemented at the local level. This section of the paper will focus on possible reasons for the failure by state level officials to take actions to implement the state policy.

Even though the legislature adopted this policy, state level officials did not cite any actions by the 
legislature or its committees which promoted the implementation of the state policy. Following policy adoption, it does not appear that the legislature communicated with OSPI on the need to implement the policy. It does not appear that interest group support for implementation of the state policy was solicited.

Because of the need for the legislature and legislative committees to discuss recently adopted statutes with the administrative agency (OSPI), it would be expected that the legislature would have assisted OSPI in implementing the statute. Activities by the legislature that might have contributed to implementation would have included 1) providing OSPI with rule-making authority for the entire statute or 2) extensive discussions with the Professional Education Office and Legal Services at OSPI to clarify each provision of the statute. It does not appear that either of these actions took place. The goals and resources of Andrews of Professional Education did not appear to be directed toward the implementation of the state policy on appraisal by subordinates. With the limited number of personnel available in the Professional Education office, Andrews appeared to be only capable of monitoring the implementation of a limited number of basic provisions of the legislative statute on school personnel evaluation. His office also seemed 
to be better able to assist in the implementation of newly adopted statutes, rather than improving or refining implementation of less recently adopted statutes.

Two comments made by Andrews seem to be open to debate. First, when asked about activities that could promote implementation of the state policy on appraisal by subordinates, Andrews seemed to place a greater importance on responding to requests for information. He appeared to take a reactive approach to information-giving, rather than taking the initiative to inform school districts about the content of the state policy. When asked about how his office could insure compliance with the state policy, Andrews stated that his office respected local control. This response appears to be inconsistent with the fundamental responsibility of OSPI to administer laws developed by the state legislature. While local control can be encouraged within the confines of state law, it would seem that a primary duty of Andrew's office would be to curb local school district activities that were in violation of state law. It would seem that if the state legislature had intended local control on the matter of appraisal by subordinates, it would never have adopted a state policy on that topic.

The lack of interest in the state policy on appraisal by subordinates by Radosevich of WEA was unexpec- 
ted. While the WEA is erequently an advocate of grievance policies in collective bargaining agreements, it did not appear to have a role in the implementation of this state policy. Even though the lack of awareness of the policy may account for the failure of WEA to promote its implementation, Radosevich indicated that she probably would not be supportive of the state policy, as it is currently worded. Radosevich's lack of support for this policy was largely due to the possibility of reprisals against subordinates, when subordinates made unfavorable appraisals of administrators.

The absence of public debate on the state policy may have contributed to insufficient consideration of some of its elements. Insufficient consideration of these elements may have resulted in a flawed policy, which would not have the sustained support of WEA. To secure the long-term support of WEA for this policy, it would seem essential to change elements of the policy that are unacceptable to the WEA. From Radosevich's perspective, changes most necessary would eliminate the possibility of reprisals against teachers for unfavorable appraisals.

The lack of awareness of the state policy appeared to have the greatest importance for Usitalo at WSSDA. Given a more clear interpretation of the requirements of 
this policy, Usitalo appeared to be prepared to inform school districts of the state policy. He also seemed prepared to assist local school districts by suggesting potential board policies and administrative procedures for implementing this policy.

McMinn, Agency Rules Analyst at Legal Services at OSPI, did not assume an active role in implementing the state policy on appraisal by subordinates. McMinn's primary role at OSPI is responding to questions about policies, not initiating implementation of state policies. While the Legal services office assists other divisions of OSPI in developing administrative rules, this rule-making function is carried out, after the legislature authorizes rule development for a particular statute. For the School Personnel Evaluation Statute, rule-making authority was restricted to a limited number of sections of the statute, not including the policy on appraisal by subordinates. Therefore, the Legal Services office could not assume an active role in facilitating clarification and implementation of the state policy on appraisal by subordinates.

Fotheringham and the school administrators association also did not appear to assume a role in the implementation of the state policy on appraisal by subordinates. One of the primary roles of this association is 
providing in-service activities to administrators. Therefore, if other agencies had promoted policy implementation, this association could have sponsored inservice activities to assist school administrators to implement this policy designed to improve administrator performance.

Analysis of Data with Models of Policy Analysis

As noted in the review of the 1 iterature, models of policy analysis can be used to explain political behavior. Models of policy analysis can be used to speculate on possible causes for the absence of activities designed to implement the state policy on the appraisal of school administrators by certificated subordinates. These models can also be used to develop recommendations on how to implement comprehensively the state policy on appraisal by subordinates.

Process and Systems Models. The process model described by Dye (1981) appears to be particularly useful in the study of the state policy on the appraisal of school administrators by subordinates. The process model serves to identify sequential patterns in the analysis of the state policy. The process model has also been instrumental in framing the research design and analysis of the results of this study. 
The present study is primarily an investigation of the implementation stage of the policy process. At this stage of the policy process, Jones (1984) advocates studying the persons administering the program and how they maintain support. The results of the present study indicate that Andrews of Professional Education is the person primarily responsible for the implementation of the state policy. Interview data indicate that he fulfilled his responsibilities by asking for information from local school districts on a limited number of provisions of the School Personnel Evaluation statute. The limited extent of assessing local compliance with the School Personnel Evaluation Statute suggests that few implementation activities were expected at the state level to ensure local compliance. The expectation of few implementation activities by OSPI may have been partly due to the failure of the legislature to provide financial support. Because of inadequate financial support, Andrews may have been unable to ensure the comprehensive implementation of the School Personnel Evaluation Statute and, more specifically, the state policy on appraisal by subordinates.

Jones' observation that intergovernmental participation contributes to differences in opinion regarding policy intent is confirmed in the present study. This 
observation is supported by Usitalo's questioning of policy requirements and issues arising from slate's interpretation of policy intent.

Using Smith's (1973) perspective on policy implementation, the failure to implement the state policy may represent the failure of the implementing organization to direct the idealized policy, as stated in statute, through environmental constraints of time, personnel, and cost to change the behavior of the target group, local school administrators.

In considering conditions that contribute to the implementation of a policy, Sabatier and Mazmanian (1979) contend that unambiguous policy directives must be specified in statute. Moreover, leaders of the implementing agency must be committed to policy goals. When assessing compliance with the School Personnel Evaluation Statute, Andrews' office did not ask local school districts to supply information on whether they implemented the strategy of appraisal by subordinates. Local districts were not asked, apparently because the policy on appraisal on subordinates was not viewed by Andrews' office as being an important component of the statute. Thus, Andrews may not have been strongly committed to the goals of the policy. Sabatier and Mazmanian also believe that the policy should be actively supported by organized interest 
groups and several key legislators. In the case of the state policy on appraisal by subordinates, none of the conditions cited by Sabatier and Mazmanian seem to have been met.

The systems model can also be used to interpret the results of the present study. Using this model, the environmental demand that brought about the formulation and adoption of this policy proposal did not appear to continue through the implementation stage. Applying Hanson's (1979) concepts to the results, the magnitude and duration of environmental forces (i.e., interest groups) may have been inadequate to affect the direction of state education bureaucracy activities to encourage the implementation of the state policy.

Institutional Model. The principles of the institutional model focus on the importance of institutional arrangements in influencing the content and impact of public policy (Dye, 1981). In the present case, reasons for the failure to implement the state policy may be evident from an examination of institutional arrangements.

Using Barton's (1961) framework, a primary external characteristic adversely affecting implementation appeared to be the apparent absence of communication regarding state policy content between the legislative and adminis- 
trative (OSPI) institutions. The absence of communication between OSPI and other institutions (i.e., LEAs, WSSDA) also appeared to impair state policy implementation. Thus, ineffectual institutional arrangements among the legislature, the state education agency, and other institutions may account for the policy process ending after policy adoption by the legislature.

Another of Barton's external institutional characteristics with possible relevance is the input of resources. The legislature provided no funding for OSPI to implement the state policy. Consequently, OSPI may have had insufficient resources to implement a substantial part of the School Personnel Evaluation statute, of which the state policy on appraisal by subordinates is a part. In analyzing the Washington state Student Learning Objective Law, Doyle (1980) has previously criticized the Washington state Legislature for failing to provide sufficient funding for implementation, ignoring the complexity of implementation, and failing to provide funding for technical assistance. These criticisms may also be valid for the statute on school personnel evaluation. The low rate of strategy implementation in LEAs might be attributed to the failure of the legislature to provide OSPI with sufficient financial resources to ensure that the strategies consistent with the state policy were compre- 
hensively implemented and evaluated.

Dentler has observed that without fiscal support from the legislature, the probability of implementation of a policy is dependent upon the quality of interaction between SEAs and LEAs. As no fiscal support was provided in the School Personnel Evaluation Statute, the implementation of the state policy was dependent upon the quality of interaction between OSPI and LEAs. Dentler lists three elements that affect the quality of interaction between the SEA and LEAs. These factors can be analyzed in the present case to determine what factors may have contributed to the failure to implement the state policy on appraisal by subordinates. First, the quality of interaction is dependent upon state control over resources for education. In Washington, the state has a great deal of control over resources for education, so this factor probably contributes positively to close OSPI-LEA interactions. The quality of interaction is also dependent upon 1) SEA attempts to determine LEA policies and practices and 2) the level of SEA technical assistance to LEAs. In these areas, state involvement may have been insufficient to insure the implementation of the policy. It is believed that the failure to implement the state policy was, in part, due to the 1) failure to develop administrative rules and regulations to guide 
implementation of the policy and 2) failure to provide information to local school districts and school administrators regarding the content of the policy.

Another facet of the quality of interaction between SEAs and LEAs, which may encourage implementation of state policy directives is the provision of sanctions for non-compliance (Turnbull, 1984). An examination of the present policy and information from the interview data indicate no clearly stated sanctions for the failure to provide the opportunity to appraise administrative performance. Therefore, failed policy implementation may have been also due to the failure to employ governmental sanctions and rewards to insure that the state policy was carried out.

Another element of inter-institutional relationships which may have contributed to the failed implementation may have been LEA administrators' dependence on OSPI for information on state policies. The failure of OSPI to transmit information about the state policy to the LEAs and the concurrent failure of LEA administrators to comply with the state policy suggests excessive dependence of local administrators on OSPI. If administrators are held responsible for implementing state educational policies in a comprehensive manner, then the administrator might consider other sources of information on educa- 
tional policies, other than OSPI communications. Close and careful study of state statutes and regulations might provide the administrator with an additional source of information on state educational policies.

Rational and Game Models. The rational and game models do not appear to be useful for the analysis of the data obtained in the present study. The rational model would probably predict that the state policy would be comprehensively implemented at the local level in response to the state policy initiative. The data clearly indicate that little, if anything, was done at the state level to promote local strategy implementation. The data also indicate that local level strategy implementation probably did not occur as a result of the policy initiative at the state level. Thus, the data illustrate the limits of rationality in the policy process. Game theory, as described by Dye (1981), also appears to have limited applicability, because the consequences of the state policy did not appear to be directly related to the actions of two opposing parties.

Incremental Model. The incremental model appears to have relevance, when speculating on reasons for Eailure to implement the state policy on appraisal by subordinates. Using the incremental model of policy analysis, the state policy on appraisal by subordinates may not 
have represented an incremental modification on currently existing evaluation policies, resulting in the failure to implement the policy. This interpretation would be in agreement with Quade's (1982) belief that policy implementation is particularly difficult, when the policy is novel and non-incremental.

Dentler's (1984) observation of increased legislative involvement in educational policy-making may also account for the failure to implement the state policy. While no evidence is available to support this contention directly, it may be speculated that increased legislative involvement coupled with the limited resources of OSPI may have prevented OSPI from promoting innovative, nonincremental changes in appraisal practices in LEAs. While increased legislative involvement in policy-making does not always result in failed implementation, the Iimited resources of the SEA may require the development of priorities. These priorities may dictate that a limited number of prominent policies will receive the amount of attention required for policy implementation.

The failure to implement the state policy may have originated at the formulation stage of the policy process. In a manner described by Lindblom (1959), policymakers may have been unable to evaluate policy alternatives and consequences, when formulating the state policy 
on appraisal by subordinates. Because of this limitation, policy-makers were unable to develop a policy that would receive sufficient support from interest groups through the implementation stage of the policy process. As noted by Radosevich of WEA, the actual state policy was a policy alternative that was unacceptable to her. With fewer constraints on rational decision-making, the legislature may have been able to develop a policy, which was more agreeable to the WEA leadership.

\section{Group Theory and the Elite Model. In speculating} on reasons for the failure to implement the state policy, elements of group theory and the elite model may have relevance to problems that may have developed at the formulation stage of the policy process. In relation to group theory, Frohock (1979) has noted that some policies represent a compromise between competing groups. In the case of the state policy on appraisal by subordinates, slate suggested that the state policy was a compromise between teacher groups and lay interest groups. Slate recollected that the state policy was introduced into statute to appease teacher groups (i.e., WEA), who perceived a majority of the provisions in the statute as being "anti-teacher". As Hanson (1979) observes, compromises between competing interest groups may often be unplanned or unwanted. Such a consequence may account 
for the present opposition of WEA's Radosevich to the state policy. As Bardach (1980) has observed, policies based upon a weak consensus at the formulation and legitimation stages may encounter difficulties in implementation. Regardless of the effects of possible compromises, any interest group support for the state policy at the formulation stage did not appear to sustain sufficient strength to insure policy implementation. Coriments of state level officials regarding factors contributing to policy implementation underline the importance of interest group involvement for comprehensive implementation of state educational policies.

The elite model may also be useful in accounting for the failure to implement the state policy on appraisal by subordinates. This usefulness may be established by integrating tenets of the elite model with Iannaccone's (1972) assertions that educational policies are frequently developed by an intellectual elite. Integrating these ideas, it may be speculated that the state policy was formulated by an intellectual elite. In formating this policy, the elite may have directed insufficient attention toward the perspective of the administrators and practitioners responsible for implementation of the state policy. Therefore, the state policy did not include elements that would assist state level adminis- 
trators to recognize the potential benefits in promoting policy implementation.

Conclusion

From the information collected from interviews of state level officials, the state level implementation of the state policy on appraisal by subordinates was not initiated. The failure to initiate policy implementation may have been due to a lack of inter-institutional communication on the content of the state policy. It does not appear that the legislature took actions to promote implementation of the state policy by OSPI. OSPI was not encouraged by the legislature to implement the state policy through informal communications, administrative rule-making authority, or the allocation of revenues to administer the policy. The non-incremental nature of the policy may have also interfered with the implementation of this policy. After adoption of the policy, no interest group support for the policy was evident. The office in the state education agency responsible for policy implementation deferred to local control, apparently because of limited resources and the low priority placed on this policy within the School Personnel Evaluation Statute.

Dewey (1947) perceived policy as a set of rules 
reflecting public interests. In the case of the present study, inadequate support for the implementation of the legislative policy was evident at the state level. It is believed that the failure of policy implementation was partially due to the opinion of some state level officials that the state policy was not in the public interest of improving educational quality. The failure to make this state policy a high priority within the school Personnel Evaluation statute indicates that state level officials did not recognize the potential importance of this policy in improving the quality of education. Even though the state policy explicitly identifies the purpose of the policy as being the improvement of administrative performance, a frequent impression given in the interviews of state level officials was that the state policy would tend to reflect or promote polarization between teacher and administrator groups.

LOCAL IMPLEMENTATION OF THE APPRAISAL STRATEGY

Rates of Response to Mailed Surveys

In order to assess the adequacy of the response rates, professional research literature was consulted. After a review of 80 studies using mailed questionnaires, Heberlein and Baumgartner (1978) found a 488 mean response rate for single or initial mailings of question- 
naires. More than one quarter of the surveys received less than a 308 response rate to single or initial mailings of questionnaires. A mean response rate of 608 was reported for all mailed surveys, which included some studies using multiple mailings and telephone follow-ups. Shipman (1972) has also reviewed response rates to mailed questionnaires. He reported response rates varying from 328 to 428 .

While not a mailed survey, Solomon (1983) conducted a survey on the use of subordinates to appraise the performance of school administrators. She obtained a 328 response rate, when she requested that her fellow administrators in her school district complete a survey on this topic.

In the present study, the response rates to the mailed surveys of local school districts, superintendents, and teachers and support staff exceeded the average for single mailings reported in the research literature. The response rates were also near the average response rates surveys using multiple mailings. Therefore, the response rates for the surveys of local school district policies, superintendents, and teachers and support staff in the present study compare favorably with response rates for questionnaires reported in the research literature. 
The response rate to the Survey of Middle Level Administrators was slightly lower than the average rate of response reported by Heberlein and Baumgartner for single mailings, but well below the mean response rate for studies with multiple mailings. It is believed that the large number of administrators initially sent the survey may partially compensate for the relatively low response rate to the Survey of Middle Level Administrators. While a comparatively smaller percentage of individuals responded to the survey, the substantial number of surveys mailed resulted in a fairly large number of respondents. The larger number of respondents may have prevented any major distortions in the data that might have resulted from a small initial mailing and a low response rate.

In accounting for the differences in response rates across each survey group (i.e., Superintendent Survey, Survey of School District Policies), the rates of response appear to be negatively related in a linear fashion to the length of the survey. This negative relationship means that the longer the survey, the lower the response rates. Heberlein and Baumgartner (1978) also found a negative relationship between size of the survey and response rates, but not to the degree found in the present study. 
In evaluating the effects of the response rates on the results, it is speculated that those responding to this survey would tend to respond more positively to questions asked of them, than those not responding. Positive responses might include affirmative responses to questions of implementation. On questions of evaluation, positive responses might result in more benefits and fewer problems being cited. In samples with relatively high response rates, it would be expected that lower implementation, fewer benefits, and more problems would be reported. In samples with lower response rates; higher rates of implementation, more benefits, and fewer problems would be expected.

Based upon the response rates obtained, it is believed that rates of implementation should be interpreted as high estimates of actual policy implementation for all school administrators in the state of Washington. The data on the evaluation of the strategy could be expected to include more benefits and fewer problems with policy implementation, than might be the case if all school personnel in the state responded to a survey of this type.

The similarity of response rates between the present study and other studies does not guarantee the external generalizability of the research findings. However, 
it is believed that this similarity provides some assurance that the response rates are adequate to assess local implementation of the state policy, particularly when limitations in the data are recognized.

\section{Local School District Policy Adoption}

The second research question addressed the extent to which local school districts adopted policies on appraisal by subordinates, pursuant to state policy. With the high proportion of local school districts responding to the survey and the very low percentage of the school districts reporting local policy adoption, a high level of confidence can be placed in the results of the survey. These results strongly indicate that local school district policies have generally not been adopted to facilitate the implementation of appraisal strategies consistent with the legislative policy on appraisal by subordinates.

It is suspected that the impetus for local policy adoption in those districts reporting adoption was the discovery of the state policy in statute by a school administrator or district lawyer. To facilitate integration of appraisal by subordinates into administrative procedures, the local school district policy was adopted. However, local adoption may not have been in re- 
sponse to the legislative policy. An alternate reason for local policy adoption may have been school board interest in promoting free information flow between administrators and teachers. In other cases, the inclusion of the requirement of appraisal by subordinates in collective bargaining agreements may have been the result of negotiations between the board and the teachers. Regardless of the impetus for local policy adoption, it does not appear that a concerted effort was made to develop local school district policies in response to the state policy.

Strategy Implementation: The Opportunity to Appraise

The surveys of local school district personnel were designed to answer the third through fifth research questions. The third research question asked to what extent school administrators have given their subordinates the opportunity to appraise their performance in a manner consistent with state policy. The surveys of school personnel indicate that only a small percentage of school administrators have implemented the strategy of giving their subordinates the opportunity to appraise pursuant to state policy.

The data to verify implementation rates show similar levels of opportunity to appraise between supervisor 
groups and corresponding subordinate groups. It is believed that the difference between the rates of opportunity to appraise reported by middle level administrators (298) and their subordinates (208) is not substantial, because both percentages clearly reflect the low level of opportunity to appraise. The slightly lower levels of opportunity to appraisal reported by the teachers and support staff, relative to the middle level administrators, can be explained by the differences in the response rates for these two groups. It is believed that higher response rates probably more accurately assess the low level of opportunity to appraise in the general population. As a higher percentage of teachers and support staff responded to the survey than middle level administrators, it would be expected that fewer teachers and support staff would report being given the opportunity to appraise.

Because of the absence of a substantial difference between the teacher/support staff group and the middle level administrator groups in the levels of opportunity to appraise, it is believed that teacher and administrator perceptions did not differ greatly on the extent of this activity. It does not appear that middle level administrators attempted to use the strategy without the teachers or support staff being aware of its use. 
Summarizing this section, the results of the mailed surveys indicate that a small percentage of school administrators gave their subordinates the opportunity to appraise their performance. The agreement between implementation rates reported by supervisors and rates reported by groups of subordinates tend to validate the finding of very limited implementation of the strategy described in state policy.

\section{Reasons for Appraisal}

As no administrators reported that appraisal activities were carried in response to state policy, the legislative policy did not appear to influence the behavior of practicing school administrators. Instead, the primary reasons for carrying out appraisal activities appears to be for 1) the administrators' personal and professional growth and 2) the improvement of the school program. Some administrators also appear to place importance on knowing the perceptions of their subordinates. School administrators, especially superintendents, realize that their subordinates have the best knowledge of what elements of the school program are working well and what are not. The failure of administrators to cite the state policy as a rationale for appraisal activities reinforces the contention that the 
legislative initiative had little or no influence on administrator behavior.

POLICY EVALUATION: AN EVALUATION OF APPRAISAL STRATEGIES MEETING THE REQUIREMENTS OF STATE POLICY

Even though the state policy initiative was not cited as the primary reason for implementing the policy, it is believed that the evaluation of behaviors meeting the requirements of the state policy can serve as data for policy evaluation. This policy evaluation can be carried out by studying the benefits and problems reported by school personnel involved in appraisal activities consistent with state policy. The policy evaluation will be integrated with professional literature on appraisal by subordinates.

\section{Attribution of Impact}

The fourth research question was designed to assess whether the impact of the strategy was due to l) the opportunity to appraise alone or due to 2) the opportunity and the appraisal. The fourth research question is as follows: To what extent do certificated subordinates actually appraise their supervisor's performance, when given the opportunity in a manner consistent with state law? Most administrators being given the opportunity to 
appraise reported that they appraised their supervisor's performance. Only half of the teachers and support staff given the opportunity actually appraised their supervisor's performance.

The differences between the middle level administrator group and the teacher/support staff group in the extent of actual involvement in appraisal activities is difficult to explain. No obvious reason seems to account for this finding. It may be speculated that middle level administrators feel less anxiety, than teachers and support staff, about appraising their supervisor's performance.

Because all administrators either giving or given the opportunity to appraise reported involvement in appraisal activities, strategy impact for this group can be attributed to the opportunity to appraise and the actual appraisal. However, because not all teachers and support staff agreed to appraise their supervisor's performance, the benefits and problems cited this group must be attributed differentially. For those choosing not to appraise, benefits and problems can only be attributed to the opportunity to appraise. For those appraising supervisor performance, the impact of the strategy can be assigned both to the opportunity and actual appraisal. 
Benefits of Appraisal Activities

In line with past researchers' recommendations for using subordinate appraisal information (i.e., Licata, 1980; Solomon, 1983), school administrators in this study were able to develop a plan of self-improvement in areas identified as weaknesses by their subordinates. A number of school administrators believed that being informed of their strengths by their subordinates helped them better capitalize on these strengths. Several teachers also recognized the appraisal process as being an opportunity to praise administrators for their accomplishments. Some administrators also agree with Bridges' (1982) model of organizational behavior and Ellett's (1977) findings that identify subordinate input as an important indicator of organizational effectiveness.

In agreement with Weldy's (1960) finding; school administrators, teachers, and support staff in the present study reported improved administrative performance, as a consequence of appraisal by subordinates. Another frequently cited benefit of appraisal activities by administrators and teachers was the creation of better learning environment for students and a better working environment for teachers.

The benefits reported by middle level administrators in the present study support the contention that 
appraisal by subordinates helps improve organizational functioning by obtaining benefits associated with a democratic leadership style. As reported by Rainey (1983), positive outcomes associated with a democratic leadership style include more accurate communication, more effective problem-solving, and improved work quality. These positive outcomes are consistent with benefits cited by middle level administrators in the present study. Middle level administrators noted better communication or rapport between teachers and administrators, when subordinates appraise administrative performance. This finding is in agreement with prior reports of Chamberlin (1980) and Solomon (1980) on benefits of appraisal by subordinates. A number of administrators also noted that appraisal by subordinates resulted in more effective problem-solving. Improved problem-solving may result from the administrator's increased awareness of subordinate perceptions on important issues. By consulting staff, the administrator may also become aware of various alternative solutions to problems.

By asking their subordinates for their opinions of administrative performance, the administrator may show that he values and respects the subordinates' opinions. Even some of the teachers and support staff electing not to appraise appreciated being given the chance to ap- 
praise administrator performance. The request for appraisal information may show that the administrator trusts the subordinates to give an accurate, objective evaluation. Increased communication, trust, and respect may result in improved morale among the certificated staff.

An examination of the responses of the teachers and support staff allow for a comparison of 1) the benefits associated with being given the opportunity to appraise and 2) the benefits related both to being given the opportunity and actually appraising administrator performance. Those choosing not to appraise appreciate being given the opportunity, but report no substantive benefits in the school environment. However, a number of teachers actually appraising administrator performance report observable improvements in the school environment. Therefore, while the opportunity to appraise may contribute to better relations between teachers and their supervisor, the actual appraisal is probably more effective in producing more widespread and observable benefits in the school environment.

In conclusion, appraisal by subordinates may enable the evaluation and improvement of administrator performance. Appraisal by subordinates may also contribute to improved communication, better problem-solving, mutual 
respect, and higher teacher morale. These benefits may contribute to a better working environment for the teacher. The same factors may also facilitate the creation of a more fertile setting for student achievement.

\section{Problems with Appraisal Activities}

Administrators and teachers reporting involvement in appraisal activities meeting policy requirements also cited problems with this strategy. School personnel reported feelings of intimidation, fear, and discomfort on the part of the subordinate. Related to this problem of anxiety, some administrators reported difficulty getting their subordinates to provide appraisal information. Other administrators report problems with their subordinates not being completely candid, when providing appraisal information.

Only 3 of 22 administrators involved in policyrelated appraisal activities reported negative evaluations of their performance by subordinates. Therefore, administrator concerns about negative bias noted in Licata's (1980) study were not supported by administrators in the present study. Moreover, the data did not corroborate Weldy's observation that appraisal by subordinates was an opportunity for some subordinates to "let off steam." 
In explaining these results, the face-to-face, confidential conference procedure described in state policy may foster anxiety in the subordinate and discourage negative evaluations of supervisor performance. This explanation is supported by the finding that some teachers and support staff choosing not to appraise indicate that a reason for their failure to evaluate their supervisor is the anxiety created by this type of appraisal. This explanation is consistent with Martin's (1979) finding that few subordinates appraised supervisor performance, when the identity of the subordinate making the appraisal was known by the supervisor.

The most significant problems cited by teachers who appraised their supervisor's performance was the supervisor's failure to follow-up on subordinate recommendations. Some teachers observed that their supervisor did not alter his/her behavior, after being provided with appraisal information. This failure to respond to the appraisal may actually worsen teacher-administrator relations. As Weldy (1960) contends, the administrator must be sincerely interested in improvement for the appraisal process to be constructive.

\section{Conclusion}

The evaluation of the strategy of appraisal by 
subordinates described in state policy indicates that this type of appraisal is beneficial for the evaluation and improvement of administrator performance. Improvements in the general school environment have also been attributed to appraisal by subordinates. The beneficial effects of this strategy attest to the need to encourage more widespread implementation of appraisal by subordinates. However, problems associated with subordinate anxiety and lack of administrator response to appraisal information indicate the need to revise elements of the state policy.

\section{SUMMARY OF DISCUSSION}

In summarizing, the results of the interviews of state level officials suggest that defects in communication between the legislature and the state education agency may have contributed to the failure to implement the state policy on appraisal by subordinates. The absence of interest group support and limited resources of the SEA may also account for the failure to encourage the comprehensive implementation of the state policy at the local level. While local school districts may have the ultimate responsibility for complying with state policy, units of the SEA appear to have a responsibility for communicating elements of this state policy to local 
school districts and personnel.

Because many education personnel at state and local levels did not appear to respond to the state policy initiative, the state policy can be regarded as having little or no impact on local practice. Reinforcing prior research in the area of appraisal by subordinates, the results of this study indicate that this type of appraisal can be important for the evaluation and improvement of administrator performance and organizational Eunctioning. The findings on the effectiveness of appraisal by subordinates attest to the value of the appraisal strategy, rather than the impact of the state policy initiative.

However, the strategy is not without its problems. Most notably, subordinates express anxiety about evaluating their supervisor's performance in a face-to-face confidential conference. Moreover, teachers and support staff observe that administrators sometimes fail to respond to appraisals of their performance. The evaluation of the appraisal strategy is suggestive of the continuation of the state policy to reap the benefits of this approach to administrator appraisal. However, the state policy should be modified to reduce problems associated with the procedure specified in policy. 
CHAPTER VI

\section{CONCLUSION}

The results of the present study illustrate a failure to implement state educational policy on a comprehensive basis. This study also points out the importance of certain factors related to the comprehensive implementation of educational policies.

The value of continuing the practice of appraisal by subordinates is strongly indicated by the results of the present study. Problems reported with strategy implementation suggest possible changes in state policy, which might increase the effectiveness of this practice.

\section{ADDRESSING THE RESEARCH PROBLEM}

In order to link the results of this study with conclusions discussed in this chapter, Table VII provides a summary of findings derived from the results of this study. A summary of this type necessarily involves oversimplification of the data by providing general trends.

Reviewing the information presented in Table VII, data collected in the present study suggest that the 
intent of the state policy was not clearly specified. Because of questions arising from interpretations provided by officials in the legislature and the state school directors' association, the intent of the state policy seems ambiguous. The most prominent issue with regard to interpretation of intent appears to be whether the appraisal strategy described in policy limits teacher input to specific areas of administrative performance.

TABLE VII

RELATIONSHIPS BETWEEN POLICY ISSUES AND THE RESULTS OF THIS STUDY

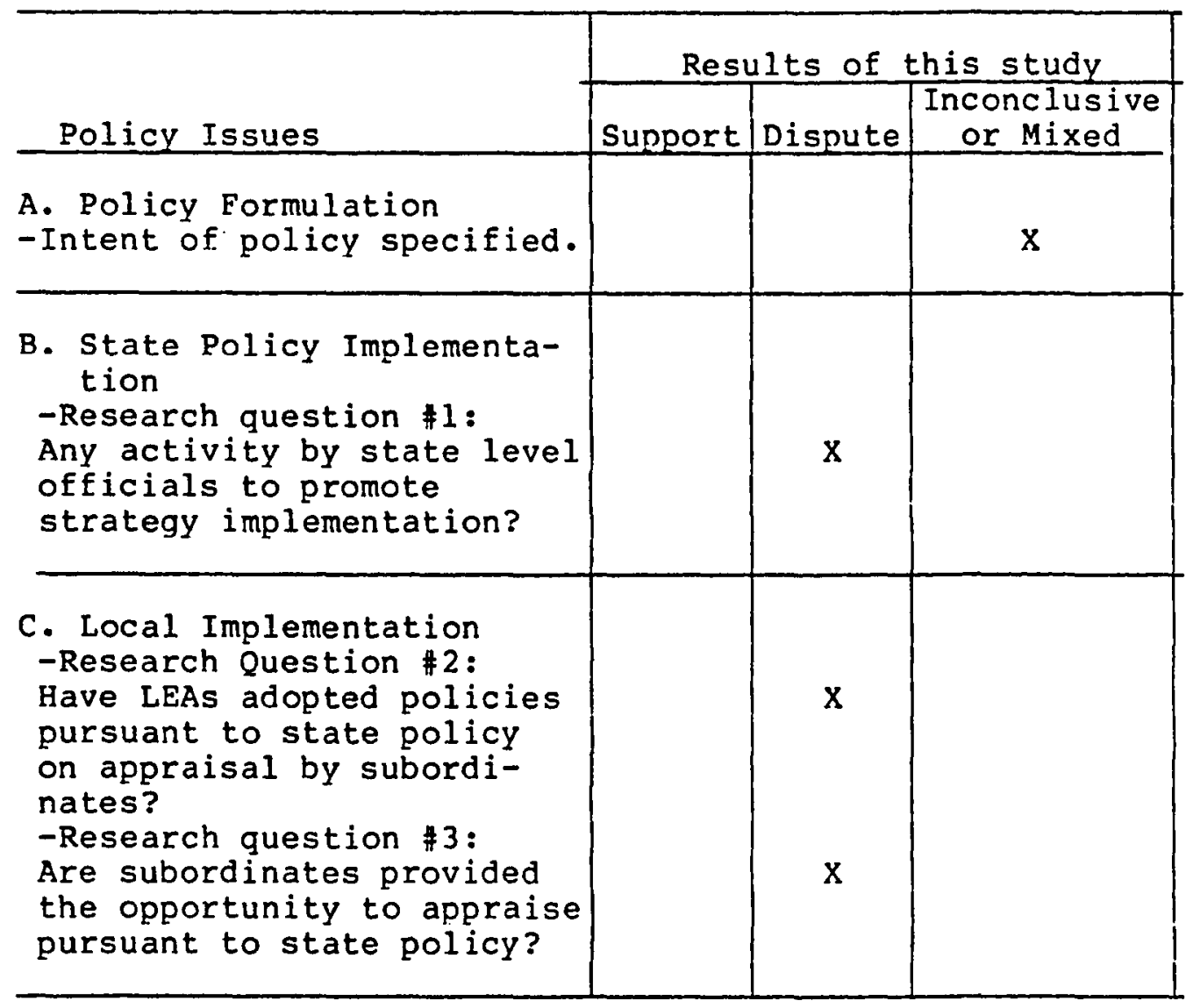


TABLE VII (continued)

\begin{tabular}{|c|c|c|c|}
\hline \multirow[b]{2}{*}{ Policy Issues } & \multicolumn{3}{|c|}{ Results of this study } \\
\hline & Support & Dispute & $\begin{array}{c}\text { Inconclusive } \\
\text { or Mixed } \\
\end{array}$ \\
\hline $\begin{array}{l}\text { D. Strategy Evaluation } \\
\text { - Research question } \# 4 \text { : } \\
\text { When given the opportunity, } \\
\text { do subordinates actually } \\
\text { appraise school administra- } \\
\text { tor performance pursuant to } \\
\text { state policy? } \\
\text { a. Administrator reports. } \\
\text { b. Teacher reports. }\end{array}$ & $\mathrm{x}$ & & $\mathrm{x}$ \\
\hline $\begin{array}{l}\text {-Research question } 5 \text { : What } \\
\text { are the attitudes of LEA } \\
\text { personnel toward strategy } \\
\text { implementation? } \\
\text { 1. Potential Benefits } \\
\text {-Assists administrator in } \\
\text { developing a plan of self- } \\
\text { improvement. } \\
\text { - Administrator provided } \\
\text { with teacher perceptions. } \\
\text { - Better communication } \\
\text { between teachers and } \\
\text { administrators, as report- } \\
\text { ed by administrators. } \\
\text { - Improved administrator } \\
\text { performance or organiza- } \\
\text { tional functioning. } \\
\text { a. Administrator reports. } \\
\text { b. Teacher reports. } \\
\text {-Increased teacher involve- } \\
\text { ment in decision-making. } \\
\text { a. Administrator reports. } \\
\text { b. Teacher reports. } \\
\text { 2. Potential Problems } \\
\text {-Excessively negative ap- } \\
\text { praisals by subordinates. } \\
\text {-Subordinates intimidated } \\
\text { or hesitant to respond. } \\
\text { a }\end{array}$ & $\begin{array}{l}x \\
x \\
x\end{array}$ & $\mathrm{x}$ & $\mathbf{x}$ \\
\hline
\end{tabular}


At the implementation stage of the policy process, the results indicated that no actions were taken by educational personnel at the state level to promote implementation of the state policy. No actions were taken to inform LEA personnel of the need to comply with the requirements of state policy.

With regard to strategy implementation, a large majority of school districts reported that they had not adopted policies to encourage administrators' use of appraisal strategies that were consistent with state policy. Moreover, a substantial portion of school administrators reported that they had not given their subordinates the opportunity to appraise their administrative performance in the manner described in state law.

Even though strategy implementation rates were low, data were provided to tentatively evaluate the merits of the strategy of appraisal by subordinates described in state policy. Because a large proportion of administrators reported that they appraised their supervisor's performance when given the opportunity, the effects of strategy impact could be attributed both to the opportunity to appraise and the actual appraisal. Because only half of the teachers and support staff appraised their supervisor's performance, when given the opportun- 
ity, the benefits and problems reported in this group were differentially attributed to 1) the opportunity to appraise alone or 2 ) both to the opportunity and the actual appraisal.

Regarding benefits of this strategy, school administrators reported that the strategy helped them evaluate their performance and assisted them in developing work performance goals. Middle level administrators reported that the appraisal strategy provided them with teacher perceptions on school issues. Administrators reported that the strategy improved decision-making and communication between staff and supervisor. Middle level administrators and teachers also reported that the appraisal strategy resulted in improved administrator and/or organizational functioning. However, some teachers reported that their supervisor failed to respond to input provided in the appraisal. Therefore, from the perspective of teachers, the impact of the strategy seems mixed with regard to improving administrator performance and increasing teacher involvement in decision-making.

Because only three administrators reported receiving negative appraisal information, the appraisal strategy cannot be associated with excessively negative evaluations by subordinates. However, school personnel reported that subordinates were anxious about providing 
appraisal information to their supervisor.

IMPLICATIONS FOR POLICY-MARING

The results of the present study have a number of implications for educational policy-making. These implications have been primarily derived from an analysis of the first research question, which addressed actions of education personnel at the state level to implement state policy. These implications have also been generated from an examination of the second research question on LEA policy adoption and the third research question on opportunity to appraise.

While primarily relevant to the State of Washington, these implications may be applicable to educational policy-making in other states. The applicability of these results to policies in other states is based upon the assertion that the failure to implement the state policy on appraisal by subordinates is not an isolated instance of failure to implement public policies. Instead, it is believed that this failure to comprehensively implement state policy characterizes the policy process of a substantial number of public policies across the nation. This contention is supported by researchers (i.e., Dentler, 1984; Quade, 1982), who have found that a substantial number of policies are either not implemented 
as intended or not implemented at al1.

From information derived in the present study, several suggestions could be made to increase the likelihood of comprehensive implementation of the state policy on appraisal by subordinates, as well as other legislative policies. During the formulation of the policy, those proposing the adoption of a state policy should consult with and seek the support of interest groups (i.e., state teachers association) that will actively promote the implementation of the policy. By consulting with interest groups, changes can be made in the policy which integrate the contents of the policy with the objectives of the interest groups. In making policies consistent with the objectives of the interest groups, the groups may be more committed to promoting the implementation of the policy. This commitment would be evident by communications on policy content to local interest group representatives and litigation in response to resistance to the policy. As Quade contends, difficulties with implementation are likely to be encountered, whenever an external solution is imposed in policy without the participation of those affected by the policy. When interest group support is not guaranteed, the provision of revenues to encourage or assist in policy implementation becomes more critical. Without the pro- 
vision of revenues in the policy, salient sanctions for failure to comply must be written into policy. Quade has recognized the importance of providing incentives to the implementing bureaucracy to increase its commitment to policy goals.

During the formulation phase and in the early stages of implementation, efforts should be made to clearly define the requirements of the policy. If the requirements of the policy in statute are insufficiently specific to enable almost direct translation into practice, then the legislature should authorize the state education agency to make administrative rules on the policy or statute. While sometimes cumbersome, administrative rules can be more easily modified to clarify unanticipated ambiguities in the legislative statute. Consultations between the state education agency and the legislature can insure that the administrative rules are consistent with legislative intent.

Whether administrative rules are adopted or not, the legislative committees must communicate very closely with the state education agency on the specific requirements of legislative statutes. It may also be important to include a representative of the school directors' association in states where the directors' association develops model board policies for local school districts. 
While these recommendations may seem very basic, the results of the present study illustrated the importance of these activities for comprehensive policy implementation. The failure to carry out these activities may effectively stop the policy implementation process.

At the local level, the present study seems to illustrate the dependence of some local school administrators on state level agencies for information and impetus to implement laws pertaining to the improvement of professional performance. While some school administrators solicit appraisal information from their subordinates, many do not. The failure to carry out this activity can be attributed, in part, to the absence of communication from the SEA to local school administrators on state policy requirements. In relation to policies generally, the state can place responsibility for compliance at the local level. However, state agencies are obligated to provide local school districts with information to encourage implementation of any meritorious policy, even though it may deviate from well-known, "traditional" management practices. The state educational agency and school boards association should not limit informationgiving to providing districts with rules and regulations. These agencies must also clearly and forcefully provide school administrators with guidance on how best to imple- 
ment policy practices. State education agencies should work cooperatively with interest groups in providing training for administrators and teachers on how to most effectively implement policies that impact them.

While the focus of the responsibility for promoting implementation of legislative policies has been placed upon state level officials, local school personnel bear ultimate responsibility for implementation of practices consistent with policy. School administrators and teachers should not be the passive recipients of educational policy. Instead, regular reviews and discussions of various elements of state policy can encourage policy implementation that has the greatest positive impact in the school environment.

\section{IMPLICATIONS FOR EDUCATIONAL PRACTICE}

The analysis of results provides implications for educational practice. These implications are primarily derived from a study of the third research question on whether subordinates are given the opportunity to appraise, the fourth research question on whether subordinates appraise when given the opportunity, and the fifth research question on the impact of appraisal by subordinates. 
The Need for Appraisal

As asserted previously, the cultivation of quality school administration is dependent upon the collection of accurate appraisal information. From a review of the professional literature, it has been found that appraisal by subordinates is one component of an effective appraisal system. The results of the present study reinforce this contention.

The failure of school administrators to implement the strategy described in state policy may represent an impediment to the assessment and improvement of school administration in the State of Washington. The failure to implement the state policy may have 1) interfered with the ability of the school administrator to assess the organizational effectiveness of the school and 2) impeded the achievement of organizational benefits associated with a democratic leadership pattern. In agreement with Valentine's (1981) finding that teachers do not feel that they have the opportunity to express opinions or concerns about school issues, the failure to implement the strategy described in state policy may indicate that teachers also have little opportunity to express concerns about school administration.

While Buser and Banks (1984) found that a large percentage of elected officials of education professional 
associations supported teacher appraisals of administrators, Solomon's (1983) report suggested more of a reluctance of school administrators to solicit appraisal information from their staffs. This study does not attempt to assess the prevalence of appraisal by subordinates using a variety of different methods. However, the results support the contention that many administrators in the State of Washington are either ignorant of practices or reluctant to implement practices on appraisal by subordinates, which are required by law.

\section{Modification of Policy Requirements}

It is believed that changes in the strategy specified in state policy could increase the effectiveness of appraisal by subordinates. These changes are suggested by reported problems with strategy implementation. The evaluation of the policy on appraisal by subordinates points out the need for procedures that minimize subordinates' feelings of anxiety. These feelings of anxiety appear to contribute to subordinates' avoidance of appraisal. To avoid these feelings, a written evaluation, completed anonymously, could be used to appraise supervisor performance. This anonymously completed evaluation could also result in more subordinates becoming involved in the appraisal process. Providing incentives to subor- 
dinates for completing this evaluation might encourage all subordinates to contribute appraisal information. The written evaluation should not only allow for ratings in specific areas of job performance, but should also enable the subordinate to respond to open-ended questions. The focus of the questionnaire should not be on the criticism of performance. Instead, its focus should be on assessing what is being done well and how to improve performance. Responsible appraisals should include statements of administrator strengths. The subordinate should also restrict the discussion of administrator weaknesses to a limited number of areas that, if changed, would result in greatest improvements in the learning environment.

It is believed that the subordinate should have the option of signing the evaluation and the opportunity for a confidential conference to discuss the appraisal with the supervisor. By signing the appraisal, the subordinate may better enable the administrator to respond constructively to the appraisal. The face-to-face dialogue of the confidential conference might represent a more effective way for the subordinate to communicate his/her views to the supervisor. In this conference, the supervisor and subordinate might discuss potential solutions to problems described in the written evaluation of super- 
visor performance.

To encourage administrator responsiveness to appraisal, a committee of subordinates could work with the supervisor in using results of written evaluations to develop and assess progress toward work performance goals. This committee might serve in an advisory capacity to the administrator's supervisor or the board of directors.

When carrying out any of these appraisal procedures, the goal should be the improvement of administrator performance, not the airing of grievances. It should be communicated to all personnel participating in the appraisal that efforts to improve administrator performance may not only benefit the administrator, but may also benefit subordinates by creating a better work environment.

While some individuals might advocate exclusive reliance on less formalized procedures for appraisal by subordinates, Solomon warns against administrators relying on incidental methods of information-gathering. Solomon cautions that administrator assumptions about the nature of organizational functioning are sometimes highly inaccurate. A formalized appraisal process was required for solomon to obtain a more accurate picture of organizational events. 


\section{METHODOLOGICAL PROBLEMS}

Certain methodological problems encountered in this study may limit the certainty and generalizability of the conclusions. Avoidance of such problems in similarly designed studies in the future may increase the power of research findings.

In relation to the interviews of state officials, a significant problem encountered was the ten year period that elapsed between the adoption of the state policy on appraisal by subordinates and the interviews of state officials. The time span between policy adoption and the interviews interfered with the reconstruction of events surrounding policy adoption. The ten year time interval may have obscured any communications between the legislature and OSPI, during policy formulation and early stages of implementation. To increase the accuracy of a description of these stages of the policy process, a reduction of the time interval between policy adoption and the study of the state policy would have have been desirable.

Another methodological problem in the present study was the differences between the samples of school personnel. The teacher and support group were sampled from the southwest region of the state of Washington, while school 
administrators were sampled statewide. Consequently, the comparability of these groups may be limited. However, the levels of opportunity to appraise reported by these groups are in agreement, providing some basis for the contention that regional differences between these groups may not be great. Nevertheless, a statewide sample of teachers and support staff would have been preferred, if it had been available.

Results obtained from the Survey of Middle Level Administrators may have more limited generalizability to the general population, because of the lower rate of response to this survey. Generalizability of results may be limited, because those responding to the survey may have a more positive view of appraisal by subordinates than those failing to respond to the survey. This bias may have inflated the rates of appraisal strategy implementation. This possible bias may have also resulted in more positive evaluations of the policy than would have been the case, if all school personnel sampled had responded to the survey.

The lower response rate for the middle level administrator survey may have been due to the longer length of this survey, relative to other surveys used in this study. By mailing this survey in June, the response rate may have been further lowered, because vacationing admin- 
istrators could not have returned the survey by the date requested.

Heberlein and Baumgartner (1978) have found that the number of mailings of questionnaires accounted for a substantial part of the variance in response rates reported by studies using mailed questionnaires. Number of mailings were defined as the number of times surveys were mailed or reminders were sent to those who had failed to respond to prior mailings. Other factors contributing to increased response rates were 1) respondents' perceived importance of the survey topic, 2) the use of special techniques (i.e., certified mail, telephone calls), and 3) the reduced length of the questionnaire. These findings point out the importance of follow-up mailings to increase the representativeness of the results. Presuming constraints associated with costs of printing and mailing surveys, more representative results may be possible by reducing the total number of surveys sent, while increasing the number of mailings to non-respondents. In the future, follow-up phone calls or letters to reinforce the need to return the survey could be used to increase response rates.

The relatively low level of appraisal strategy implementation may have also interfered with an accurate view of the merits and problems of this strategy. The 
small percentage of respondents using this strategy may have resulted in a sample, which was unrepresentative of the general population. In the future, information on impact of appraisal strategies would have greater power with a higher rate of implementation.

In summary, the time interval between policy adoption and the interviews of state officials interfered with an accurate reconstruction of the events surrounding the adoption and early implementation of the state policy on appraisal by subordinates. Moderate response rates to administrator surveys may have affected the estimate of local level strategy implementation, while small sample sizes may have interfered with the accuracy of the evaluation of strategy impact.

\section{DIRECTIONS FOR FUTURE RESEARCH}

This study is believed to provide definitive conclusions on the first three research questions on policy implementation. Because of the relatively low rates of appraisal strategy implementation, the results on research questions four and five should be regarded as tentative. Additionally, the present study represents an exploratory study on the general practice of appraisal by subordinates, because this study examined only one strategy of appraisal by subordinates. More definitive stud- 
ies on the general practice of appraisal by subordinates would probably require the study of a variety of techniques for the appraisal of administrators by subordinates. Evaluative data collected in the present study provides bases for speculating on effective appraisal practices. However, additional research is necessary to determine whether the practices suggested by the results of the present study bring about improvements in the appraisal process. Thus, the study of effective methods for the appraisal of school administrators by subordinates appears to be a fertile area of research. In addition to studying a variety of different methods of appraisal, different measures could be used to judge the usefulness of appraisal information and activities. An attempt might be made to isolate various elements of strategies, which appear to create specific benefits in the school setting. Forced choice response formats might be used in survey research methods, so that the opinions of all participants involved in the appraisal strategy could be assessed in a uniform manner. Special emphasis could be placed on determining the effectiveness of appraisal methods in bringing about objective and constructive changes in administrator performance. More detail on the nature of differences between the perceptions of teachers and administrators on policy 
impact might be assessed in future studies of appraisal strategy impact. Factors contributing to these differences in perceptions might be studied.

Future mailed survey research on the strategy of appraisal by subordinates could be designed to improve the techniques for increasing response rates and obtaining more representative results. Follow-up postcards encouraging response or multiple mailings of the surveys could be utilized. Associating the survey with university or institutional research might also increase the likelihood of response.

In relation to policy analysis, the results of the present study point out the need for further study of conditions that contribute to implementation of legislative policy initiatives by SEA bureaucrats. By further study of the conditions contributing to policy implementation, policy-makers might avoid making policies that have a low probability of implementation or modify policies to increase the probability of implementation. A more uniform, yet comprehensive, implementation of state policies might be possible.

Future research might address efforts taken by legislatures to develop policies that include elements that encourage and enable comprehensive policy implementation. The study of conditions which contribute to the 
inclusion of these elements in policy might also be useful. Research might also study the extent of legislative policies requiring evaluation of policy impact. Further study is also needed to specify the conditions, which contribute to the enactment legislative provisions for the study of policy impact.

\section{SUMMARY OF CONCLUSIONS}

In summarizing, problems in the implementation of the state policy on appraisal by subordinates illustrates the importance of factors that contribute to policy implementation. Comprehensive policy implementation will be encouraged by the involvement of interest groups in policy formulation and implementation phases of the policy process. Funding to promote policy implementation or salient sanctions for non-compliance can also serve to promote implementation. Legislative authorization to the state education agency to make administrative rules on all elements of a statute might enable better clarification and easier modifications of policies. Following legislative adoption of a statute; the legislature, the state education agency, and representatives of interest groups should meet to discuss what actions can be taken to promote implementation of all elements of the statute at local levels. 
Since Weldy's early study on this topic, the most fundamental elements of a successful appraisal of supervisor performance remain unchanged. The successful appraisal continues to be dependent upon a responsible and constructive attitude on the part of the teacher and a sincere interest in improvement on the part of the supervisor. The primary goal must be the improvement of administrator performance. With this goal, the activity may benefit the supervisor and the subordinates. The benefits associated with appraisal by subordinates suggest the need to implement such appraisal strategies on a comprehensive basis.

However, the evaluation of the state policy illustrates the need for administrators to respond to the evaluation of their performance. If the administrator does not acknowledge and respond to the needs voiced by the staff, then the appraisal may represent a meaningless activity for the building staff and may contribute to lower teacher morale.

Problems with policy requirements provide the basis for modifying these requirements and improving the appraisal process. To reduce feelings of anxiety, an anonymously completed questionnaire could be used to appraise supervisor performance. The administrator might be better able to respond constructively to suggestions, if the 
subordinate was given the option to 1) sign the evaluation or 2 ) have a confidential conference with the administrator. A committee of subordinates might work with the supervisor in responding to the results of the written questionnaire.

A primary methodological problem of the present study was the long interval of time between policy adoption and the interviews of state officials. This problem interfered with an accurate reconstruction of the events surrounding the adoption and early implementation of the state policy on appraisal by subordinates. Moderate response rates to administrator surveys may have affected the estimate of local level strategy implementation. Moderate response rates and small sample sizes may have interfered with the accuracy of the evaluation of policy impact.

So more representative data can be obtained, it is suggested that future mailed survey research on the topic of appraisal by subordinates integrate procedures that will increase the rates of response to surveys. Future research is also needed to study the effects of a number of different approaches to collecting appraisal information from subordinates. A variety of different measures should be used to assess the effects of varying elements of the appraisal strategies. 
Future research is needed to specify the extent to which legislative bodies include provisions that encourage policy implementation and evaluation. It would also be desirable to specify the conditions under which legislative bodies are likely to include these provisions in policy. 
REFERENCES

Bailey, G. (1984). Faculty feedback for administrators: A means to improve leadership behavior. National Association of Secondary School Principals Bulletin, 68, 5-9.

Bailey, S., \& Mosher, E. (1968). ESEA: The office of Education Administers a Law. Syracuse: Syracuse Univ. Press.

Bardach, E. (1980). On designing implementable programs. In G. Majone \& E. Quade (Eds.), Pitfalls of Analysis. Chicester: Wiley.

Barton, A. (1961). Organizational Measurement. Princeton, N.J.: College Entrance Examination Board. Cited in F. Frohock (1979), Public Policy. Scope and Logic. Englewood Cliffs, N.J.: Prentice-Hall, Inc.

Beaubier, E., \& Thayer, A. (1973). Project leadership. Assessment alternatives. Association of California School Administrators. ERIC Document Reproduction Service No. ED 180116.

Beuke, V. (1980). Implementation of the Education Amendments of 1976: A study of state and local compliance and evaluation practices. Final report. ABT Associates Inc., Cambridge, MA. ERIC Document Reproduction Service No. ED 200 785 .

Beyer, J., Stevens, J., Trice, H. (1983). The implementing organization: Exploring the black box in research in public policy. In $R$. Hall and $R$. Quinn (Eds.), Organizational Theory and Public Policy. Beverly Hills: Sage.

Blaschke, C. (1981). PL 94-142: A study of the implementation and impact at the state level. Vol. I. Final Report. Education Turnkey Systems Inc., Falls Church, VA. ERIC Document Reproduction Service No. ED 206151 .

Boyan, N. (1981). Follow the leader: Commentary on research in educational administration. Educational Researcher, 17, 6-13. 
Boyd, W., \& Immegart, G. (1979). Education's turbulent environment and problem finding: Lines of convergence. In G. Immegart and W. Boyd (Eds.), Problem-finding in Educational Administration: Trends in Research and Theory. Lexington, Mass.: D.C. Heath.

Bridges, E. (1982). Research on the school administrator: The state of the art, 1967-1980. Educational Administration Quarterly, 18(3), 12-33.

Buser, R., \& Banks, F. (1984). The why, what, how and by whom of evaluating principals. National Association of Secondary School Principals Bulletin, $\underline{68(468), 1-4 .}$

Chamberlin, L. (1980). Project SAFE (Survey of Administrative Functional Efficiency). A feedback project to assist principals. Bowling Green Univ. ERIC Document Reproduction Service No. ED 185668 .

Cistone, P. (1976). Education's new politics - Getting to know your bedfellows. National Association of Secondary School Principals Bulletin, 60, 4-8.

Cross, R. (1981). What makes an effective principal? Principal, 60(4), 19-22.

Deal, T., Dornbusch, S., \& Crawford, R. (1977). Villians as victims: Evaluating principals. Phi Delta Kappan, 59(4), 273-274.

Dentler, R. (1984). Ambiguities in state-local relations. Education and Urban Society, 16(2), 145164 .

Dewey, J. (1947). The Public and Its Problems. An Essay in Political Inquiry. Chicago: Gateway Books.

Doyle, V. (1980). Curricular focus and change through mandate: The State of Washington approach. $\mathrm{Pa}$ per presented at the Annual Meeting of the American Educational Research Association (Toronto, Ontario, March 27-31, 1978). ERIC Document Reproduction Service No. ED 154502 .

Dye, T. (1981). Understanding Public Policy, (4th Ed.). Englewood Cliffs, N.J.: Prentice-Hall. 
Ellett, C. (1977). Teacher assessments of principals' performances: Their validity and independence of school size and other characteristics. Salt Lake City: Utah Univ., Dept. of Educational Administration. ERIC Document Reproduction Service No. ED 146703 .

Elliot, T. (1959). Toward an understanding of public school politics. American Political Science Review, 52, 1032-51.

ERIC Clearinghouse on Educational Management. (1980). Principal evaluation. Research brief number 12. Eugene, OR: ERIC Clearinghouse on Educational Management. ERIC Document Reproduction Service No. ED 193742 .

Etzioni, A. (1973). Mixed scanning: A 'third' approach to decision making. In J. Jun \& W. Storm (Eds.), Tommorrow's Organizations: Challenges and Strategies. Glenview, Ill.: Scott Foresman. Cited in E. Hanson (1979), Educational Administration and Organizational Behavior. Boston: Allyn \& Bacon, Inc.

Featherstone, R. \& Romano, L. (1977). Evaluation of administrative performance. Clearinghouse, 50(9), 412-415.

Frohock, F. (1979). Public Policy. Scope and Logic. Englewood Cliffs, N.J.: Prentice-Hall, Inc.

Gorton, R., \& McIntyre, R. (1978). The senior high principalship. Volume II: The effective principal. Reston, Virginia: National Association of Secondary School Principals. ERIC Document Reproduction Service No. ED 158440.

Hall, R., \& Quinn, R. (1983). Question: Is there a connection between organizational theory and public policy? In R. Hall and R. Quinn (Eds.), Organizational Theory and Public Policy. Beverly Hills: Sage.

Hamburger, H. (1979). Games as Models of Social Phenomena. San Francisco: W.H. Freeman \& Co.

Hanson, E. (1979). Educational Administration and Organizational Behavior. Boston: Allyn \& Bacon, Inc. 
Heberlein, T. \& Baumgartner, R. (1978). Factors a $\bar{f}-$ fecting response rates to mailed questionnaires: A quantitative analysis of the published literature. American Sociological Review, $43(4), 447-$ 462 .

Heflin, J. (1978). An introduction to educational policy studies research. A paper presented at a pre-session training workshop of the Special Interest Group: Research Focus on Black Education. At the annual meeting of the American Educational Research Association, Toronto, Ontario, March 26-27, 1978.

Heflin, J. (1981). Perspectives on Policy Analysis. A paper presented at the Northwest Regional Educational Laboratory/ESEA Title I Technical Assistance Center Staff Retreat. Newport, OR., June 30-July 2, 1981 .

Hersey, P., Blanchard, R., \& Hambleton, R. (1980). Contracting for leadership style: A process and instrumentation for building effective work relationships. In P. Hersey \& J. Stinson (Eds.), Perspectives in Leader Effectiveness. Center for Leadership Studies, Ohio State Univ.

Hunt, J., \& Buser, R. (1977). Evaluating the principal - Partnership or paternalism? National Association of Secondary School Principals Bulletin, 61 $(413), 10-15$.

Iannaccone, I. (1967). Politics in Education. New York: Center for Applied Research in Education.

Iannaccone, L. (1972). Increasing irresponsibility in education: A growing gap between policy planning and operational groups. In M. Rirst (Ed.), State, School, and Politics; Research Directions. Lexington, Mass: D.C. Heath.

Jones, C. (1984): An Introduction to the Study of Public Policy (3rd Ed.). Monterey, CA.: Brooks Publishing Co.

Ratz, D., \& Rahn, R. (1966). The Social Psychology of Organizations. John Wiley \& Sons, Inc. Cited in E. Hanson's (1979), Educational Administration and Organizational Behavior. Boston: Allyn \& Bacon, Inc. 
Killalea Associates. (1978). 1978 elementary and secondary schools civil rights survey: Ãnalysis of selected civil rights issues. Vol. 1 , Reports for ranked districts in the nation. Arlington. VA. Office for Civil Rights (DHEW), Washington, D.C. ERIC Document Reproduction Service No. 185 215 .

Kirst, M. (1970). Strategies for research: The politics of education. Delivered at the Annual Meeting of the American Educational Research Association, Minneapolis, Minn., March, 1970 .

Kirst, M., \& Mosher, E. (1969). Politics of education. Review of Educational Research, 39(5), 623-640.

Kuhn, T. (1970). The Struture of Scientific Revolutions. Chicago: University of Chicago Press.

Licata, J. (1980). Systemic appraisal of educational leadership personnel. Informal publications. Columbus: Ohio State Univ.., Mershon Center. ERIC Document Reproduction Service No. ED 197 423 .

Licopoli, L. (1983). Local school district implementation of state mandated educational regulations, the least restrictive environment provisions. Implications and recommendations for policy makers and educators. ERIC Document Reproduction Service No. ED 232263.

Lindblom, C. (1959). The science of muddling through. Public Administration Review, 19. Cited in E. Hanson (1979), Educational Administration and Organizational Behavior. Boston: Allyn \& Bacon, Inc.

Lovell, J., \& Phelps, M. (1977). Supervision in Tennessee as perceived by teachers, principals and supervisors. Educational Leadership, 35(3), 226228 .

Mann, D. (1985). Principals, leadership, and reform. Education Week, December 18, 1985 .

Martin, J. (1979). Staff evaluation of supervisors. Special Libraries, $70(1), 26-29$. 
Massachussetts State Department of Education. (1982). A design for evaluating the implementation of the basic skills improvement policy. Bureau of Research and Assessment, Boston. ERIC Document Reproduction Service No. ED 221564.

May, J., and Wildavsky, A. (1978). The Policy Cycle. Beverly Hills: Sage Publications.

McDonald, M., Owens, R., \& Harrison, S. (1979). Administrator evaluation: A look at Georgia and the nation. Georgia Professional Standards Commission Issues for Education Series. Atlanta: Georgia Professional Standards Commission. ERIC Document Reproduction Service No. ED 180106.

McGregor, D. $(1960)$. The Human Side of Enterprise. New York: McGraw-Hill.

McLaughlin J., \& London, S. (1979). Surrogate parenting: The extent to which state education agencies have begun to comply. Exceptional Children, $(\underline{46}) 3,211-216$.

Mood, A. (1983). Introduction to Policy Analysis. New York: North-Holland.

Mosher, E. (1980). Politics and Pedagogy: A new mix. Educational Leadership, 38, 110-111.

Myers, J. (1972). Fundamentals of Experimental Design (2nd Ed.). Boston: Allyn and Bacon, Inc.

Quade, E. (1982). Analysis for Public Decisions (2nd Ed.). New York: North-Holland.

Rainey, E. (1983). How to communicate with your professional staff: Build the proper climate. Paper presented at the National School Boards Association Convention (San Francisco, CA, April 23-26, 1983). ERIC Document Reproduction Service No. ED 242010 .

Rainey, H., \& Milward, H. Public organizations: Policy networks and environments. In $R$. Hall and $R$. Quinn (Eds.), Organizational Theory and Public Policy. Beverly Hills: Sage.

Reinert, H. (1985). Personal communication. 
Sabitier, P. \& Mazmanian, D. (1979). The conditions of effective implementation: A guide to accomplish ing policy objectives. Policy Analysis, $\underline{5}, 481-$ 504 .

Sanacore, J. (1976). How teachers can evaluate their principal. National Association of Secondary School Principals Bulletin, 60(402), 98-101.

Sapone, C. (1981). Appraisal and evaluation systems: Perceptions of administrators, teachers. National Association of Secondary School Principals Bulletin, 65(442), 25-30.

Scott, W. (1981). Organizations: Rational, natural, and open systems. Englewood Cliffs, N.J.: Prentice-Hall. Cited in E. Bridges (1982), Research on the school administrator: The state of the art, 1967-1980. Educational Administration Quarterly, $18(3), 12-33$.

Shipman, M. (1972). The Limitations of Social Research. London: Longman.

Skopec, E. (1984). Rhetorical dimensions of performance appraisal interviews. Paper presented at the Annual Meeting of the Eastern Communication Association (75th, Philadelphia, PA, March 8-11, 1984). ERIC Document Reproduction Service No. ED 241985 .

Slate, D. (1986). Personal communication.

Smith, J., \& Tawney, J. (1983). Compliance monitoring: A dead or critical issue. Exceptional Children, 50(2), 119-127.

Smith, T. (1973). The policy implementation process. Policy Sciences, $\underline{4}(2), 197-209$.

Solomon, G. (1983). Teachers rating principals: A sobering experience. Principal, 62(4), 14-17.

Sorenson, G., \& Chapman, D. (1985). School compliance with federal law concerning the release of student records. Educational Evaluation and Policy Analysis, $\underline{7}(1), 9-18$.

Superintendent of Public Instruction. (1985). Washington Education Directory. Seattle, WA: Barbara Krohn and Assoc. 
Swan, B. (1980). A study of faculty staff reactions to three types of leadership. Journal of Educational Administration, XVIII (2), 283-287.

Thomas, N. (1975). Education in National Politics. New York: D. McKay Co.

Thompson, J. (1976). Policymaking in American Public Education: A Framework for Analysis. Englewood Cliffs, N.J.: Prentice-Hall

Turnbull, B. (1984). States propose, schools dispose. Prospects for state initiatives in producing quality improvements. Education and Urban Society, 16(2), 207-224.

Urbanski, A. (1986). Lessons learned from evaluating administrators. Education Week, February 26, 1986.

Valentine, J. (1981). Do your teachers really understand you? National Association of Secondary School Principals Bulletin, 63(423), 100-111.

Van de Yen, A. (1983). Three Rs of administrative behavior: Rational, random, and reasonable (and the greatest of these is reason). In $R$. Hall and R. Quinn (Eds.), Organizational Theory and Public Policy. Beverly Hills: Sage.

Washington office of the State Superintendent of Public Instruction (1981). Citizens handbook on the organization and financing of the Washington public school system. Revised. Olympia, WA. ERIC Document Reproduction Service No. ED 208 474 .

Weldy, G. (1960). Teachers evaluate their principal. National Association of Secondary School Principals Bulletin, 45(267), 145-150.

Wirt, F. (1979). The uses of political science in the study of educational administration. In G. Immegart and $w$. Boyd (Eds.), Problem-finding in Educational Administration: Trends in Research and Theory. Lexington, Mass.: D.C. Heath.

Wuhs, S., \& Manatt, R. (1983). The pace of mandated teacher evaluation picks up. American School Boards Journal, $170(5)$, p. 28 . 
Zakrajsek, B. (1979). Evaluation systems: A critical look. National Association of Secondary School Principals Bulletin, 63(423), 100-111. 
APPENDIX A

A FORMAT FOR THE INTERVIEWS OF STATE GOVERNMENT

AND PROFESSIONAL ASSOCIATION OFFICIALS

\section{General Purpose}

1. What are the primary goals of your office/association?

Relationship to Governmental Units and Professional Associations

(Note: Individuals will not be asked questions about their own agency in this section.)

2a. What contacts has your office typically had with the state legislature? What were the topics or issues discussed in these contacts?

2b. through g. (Questions, similar to those included in $2 a$., were asked about the following agencies: $2 b$. education committee personnel in the state legislature, 2c. Office of the Superintendent of Public Instruction, 2d. State Board of Education, 2e. Washington Education Association, $2 \mathrm{f}$. Washington Association of School Adminstrators, 2g. local school districts.)

Information Giving and Receiving

3. What functions does your office serve in terms of monitoring and influencing the formulation of state legislation?

4. What functions does your office serve in terms of providing information to teachers or administrators regarding the content of state statutes and administrative regulations?

5. What functions does your office serve in terms of reviewing compliance with state statutes and administrative regulations in local school districts?

6. What functions does your office serve in terms of assessing the impact (benefits and problems with) of state statutes and administrative regulations in local 
school districts?

Activities Relating to the Policy on Appraisal of School Administrators by Subordinates

7. Are you aware of any actions by state agencies or associations to disseminate information regarding the content of this policy? If so, describe.

8. What do you perceive are the responsibilities of your office/association in providing this information?

9. What do you perceive are the responsibilities of your office/association in assessing local implementation and compliance with this provision?

10. What do you perceive are the responsibilities of your office/association in determining the impact of local implementation of this statute (i.e., benefits and problems with the implementation)?

11. What sanctions should be applied for failure to comply with the policy on the appraisal of school administrators by certificated subordinates?

Factors Contributing to the Implementation of Legislative Statutes

12. What factors contribute to the implementation of legislative statutes? 
APPENDIX B

SURVEY OF LOCAL SCHOOL DISTRICTS AND COVER LETTER

(REVERSE OF POST CARD)

PLEASE RESPOND TO THE FOLLOWING QUESTION:

Does your school district have a board policy which gives each certificated employee the opportunity to have two or more confidential conferences annually with his/her supervisor for the sole purpose of aiding the administrator in his/her professional performance?

Yes

No

Comments: 
June 24,1986

3009 E. 33rd St. Vancouver, WA 98661

\section{Dear School Administrator:}

The purpose of this letter is to request information on your district personnel policies. Specifically, I am interested in whether your school district has board policies providing for the appraisal of school administrators by their certificated subordinates (i.e., teachers). Your school district and 99 other districts were selected at random from a list of school districts in the State of Washington. I need this information for part of my doctoral dissertation on administrator appraisal.

In order to contribute information for this study, please complete the reverse of the enclosed post card. please return the post card as soon as possible.

The information you provide will be used for research purposes only. To insure your anonymity, discussions of these results will be limited to analyses of group trends. A brief summary of the research findings of this study will be sent to you, when the study is completed.

The completion and return of the enclosed questionnaire are very important to me, since the completion of my dissertation depends upon the data I am requesting. I appreciate your support and thank you, in advance, for your assistance.

sincerely yours,

Curtis Miller Doctoral Candidate 
APPENDIX C

SURVEY OF MIDDLE LEVEL SCHOOL ADMINISTRATORS

1. What is your position?

Principal

Special Education Administrator

Other (Please describe)

Please indicate the categories of certificated staff you directly supervise (check one or more)?

Teachers

Certificated Administrators

Other (Indicate certificated employees only):

2. What is your opinion of having your certificated subordinates appraise your performance and provide you with suggestions on how you might improve your performance? Please describe experiences or perceptions that support your opinion.

3a. Do you give your immediate certificated subordinates (i.e., teachers) the opportunity to have two or more confidential conferences per year with you for the sole purpose of aiding you in your administrative performance?

For example, do you ask your subordinates if they would like to provide you with suggestions or feedback about your performance at least twice a year?

Yes (If yes, continue with item $3 b$ on the reverse)

No

(If no, continue with question 4)

Comments: 
3b. For what reason do you give your certificated subordinates the opportunity to provide you with suggestions for your professional improvement?

$3 c$. When given the opportunity, do your certificated subordinates (i.e., teachers) actually agree to have confidential conferences with you for the sole purpose of aiding you in your professional performance?

For example, do any of your subordinates actually provide you with suggestions or feedback about your performance, when given the opportunity?

Yes

No

Comments :

3d. What benefits have been obtained from giving your certificated subordinates the opportunity to assist you in the improvement of your professional performance?

3e. What problems have you experienced with providing your certificated subordinates with the opportunity to assist you in the improvement of your professional performance? 
4. Do you currently hold a Washington State Teacher, Educational Staff Associate, or Administrator certificate?

Yes No

5. What is the position of your immediate supervisor?

6. Does your immediate supervisor give you the opportunity to have two or more confidential conferences per year with $\mathrm{him} / \mathrm{her}$ for the sole purpose of aiding his/her professional performance? For example, does your supervisor give you the opportunity to provide him/her with suggestions or feedback about his/her performance at least twice a year?

Yes

No

Comments :

7. When given the opportunity, do you actually agree to have confidential conferences with your supervisor for the sole purpose of aiding in his/her professional performance?

For example, do you actually provide your supervisor with suggestions or feedback, when given the opportunity?

Yes

No

Comments :

PLEASE RETURN THE SURVEY IN THE ENVELOPE PROVIDED 
Dear School Administrator:

The purpose of this letter is to request information on the practices you use to assess your professional performance. Specifically, I am interested in whether you give your certificated subordinates opportunities to provide you with suggestions on how to improve your performance. I am also interested in your opinions about such practices. In addition, I am interested in your supervisor's appraisal practices.

You and 199 other school administrators were selected at random from a list of school administrators in the state of Washington. I need this information for part of my doctoral dissertation on administrator appraisal.

In order to contribute information for this study, please complete the enclosed questionnaire. It probably will take no more than ten minutes to complete the survey. Please return the questionnaire in the enclosed envelope, no later than July 17 th.

The information you provide will be used for research purposes only. Your responses to individual survey items will not be divulged. To insure your anonymity, discussions of these results will be limited to analyses of group trends. I am not representing any school or service district in conducting this research. Morever, I am not financially supported in this research by any such agency. If requested, a brief summary of the research findings of this study will be sent to you, when the study is completed.

The completion and return of the enclosed questionnaire are very important to me, since the completion of my dissertation depends upon the data I am requesting. I appreciate your support and thank you, in advance, for your assistance.

sincerely yours,

Curtis Miller Doctoral Candidate 